\title{
The Trouble with Boys: Social Influences and the Gender Gap in Disruptive Behavior
}

\author{
Marianne Bertrand \\ (Booth School of Business, NBER, CEPR and IZA) \\ Jessica Pan \\ (National University of Singapore)
}

October 2011

\begin{abstract}
This paper explores the importance of the home and school environments in explaining the gender gap in disruptive behavior. We document large differences in the gender gap across key features of the home environment - boys do especially poorly in broken families. In contrast, we find little impact of the early school environment on non-cognitive gaps. Differences in endowments explain a small part of boys' non-cognitive deficit in single-mother families. More importantly, non-cognitive returns to parental inputs differ markedly by gender. Broken families are associated with worse parental inputs and boys' non-cognitive development, unlike girls', appears extremely responsive to such inputs.
\end{abstract}




\section{Introduction}

There has been a recent wave of interest in the role that non-cognitive skills might play in explaining educational achievement, labor market success and other significant life outcomes. Jencks et al (1979) were among the first to document that factors such as study habits, industriousness and perseverance matter as much as cognitive skills in explaining occupational achievement. Since then, other studies have confirmed the central role played by behavioral and socio-emotional factors in explaining schooling and labor market outcomes (Heckman and Rubinstein 2001; Heckman, Stixrud and Urzua 2006; Flossmann, Piatek and Wichert 2006; Segal 2011).

Table 1 confirms some of these earlier findings. Using data from both the National Educational Longitudinal Survey (NELS) and the National Longitudinal Survey of Youth (NLSY 97), we show a negative relationship between the likelihood of school suspension and multiple future educational outcomes, even after controlling for math and reading test scores. In Panel A of Table 1, we analyze educational outcomes among the sample of NELS students who were in eighth grade in 1988. The dependent variables are whether these students graduated from high school (column 1), attended college (column 2) or completed college (column 3) within 12 years of eighth grade. The key independent variable is whether the student was ever suspended from school in the first half of the survey semester or quarter in tenth grade; we control for reading and math scores in tenth grade. Additional control variables include gender, race and birth year dummies. In all specifications, we observe a negative relationship between school suspension and future educational outcomes. Moreover, all specifications yield statistically significant correlations. For example, the likelihood of at least one suspension decreases the likelihood of completing high school by 17 percentage points; the likelihood of attending college by 16 percentage points and decreases the likelihood of being a college graduate by 9 percentage points. Panel B of Table 1 reports similar relationships among a sample of NLSY children in grades 8 to 11 in 1997. Again, all specifications indicate negative relationships between suspension and educational achievement by 2007, even after controlling for ASVAB math and 
reading scores. ${ }^{1}$ In summary, the evidence in Table 1 supports the view that non-cognitive deficiencies, to the extent that they are adequately proxied for by school suspension, are important drivers of future educational outcomes.

But what determines non-cognitive skills? A large and growing body of research has already highlighted one important determinant of behavioral and socio-emotional development: gender. Boys are known to perform worse than girls on many non-cognitive dimensions. Boys have welldocumented attention and behavioral difficulties (Beamen et al., 2006; Entwisle et al., 2007; Gilliam, 2005; Ready et al, 2005) and are more likely to be diagnosed with attention deficit hyperactivity disorder (ADHD) (see for example Szatmari, 1989). In a meta-analysis of the psychology literature on gender differences in temperament, Else-Quest et al (2006) document lower levels of inhibitory control and perceptual sensitivity among boys, consistent with a greater incidence of externalizing behavior. In another meta-analysis of 33 delay-of-gratification studies, Silverman (2003) reports a small but reliable advantage that favors girls. This gender gap in non-cognitive skills also manifests itself in the higher incidence of arrest rates among teenage boys compared to teenage girls in the NLSY data (Goldin et al., 2006). In fact, a few recent papers (see for example Becker, Hubbard and Murphy, 2010) have claimed that the (reverse) gender gap in college attendance that currently exists in the US and many other developed countries might be best explained by gender differences in non-cognitive skills. In support of this claim, Jacob (2002) shows that controlling for the greater incidence of school disciplinary and behavioral problems among boys explains a substantial share of the female advantage in college enrollment. ${ }^{2}$

What is less well understood are the sources of the gender gap in non-cognitive skills. Some researchers have stressed biological influences - many of the differences that exist between male and female brains have been shown to occur in areas related to mood, emotions, and emotion regulation. The development of the frontal cortex (which is associated, among other things, with

\footnotetext{
${ }^{1}$ ASVAB refers to the Armed Servicocational Aptitude Battery test administered by the United States Military to determine qualification for enlistment in the US armed forces.

${ }^{2}$ See also Duckworth and Seligman (2005) and Kenney-Benson, Pomerantz, Ryan, and Patrick (2006).
} 
inhibitory control and hence a decreased risk of externalizing problems) and temporal lobe has been shown to be considerably faster among girls than boys. Moreover, prior research has established that variation in in-utero exposure to sex hormones, particularly testosterone, is associated with such structural and functional brain differences, even within gender groups. Higher levels of prenatal exposure to testosterone have been linked to slower maturation of parts of the temporal cortex, but also lower empathy levels, higher disinhibition and lower quality of social relationships (see for example Baron-Cohen, 2002, 2003; Geary, 1998, 2002; Keenan and Shaw, 1997; McClure, 2000; Knickmeyer et al, 2005; Maccoby, 1998).

Nevertheless, it remains unclear whether systematic gender differences in child-rearing inputs or in the production function of non-cognitive skills are also contributing factors. The primary goal of this paper is to assess the explanatory power of such social or environmental influences for the gender gap in non-cognitive development. In particular, we focus on externalizing behaviors, which encompass disruptive and acting-out behaviors such as aggression and delinquent behavior.

A case for the importance of social influences is warranted in light of earlier work showing that non-cognitive skills are not fixed but are in fact quite malleable, and can be shaped by early intervention programs. For example, in their study of the Perry preschool program, which was targeted toward disadvantaged inner-city youth, Heckman et al. (2011) document sizable increases in future employment and earnings among treated children and attribute most of these gains to the program's positive long-run effect on non-cognitive development. In a similar vein, Chetty et al. (2010) study the long-run effects of the Tennessee STAR class size experiment and document that increases in kindergarten class quality increased earnings, college attendance, and other long-run outcomes even though gains in test scores faded over time. They show that the long-run effects of kindergarten class quality operate primarily through the non-cognitive channel by increasing effort, motivating initiative, and reducing disruptive behavior. Also, using data on boys from the NELS, Segal (2008) shows that family and school characteristics are important determinants of youth behavior in the classroom.

Yet, existing research lacks a systematic look into whether and how the home and school environments contribute to gender differences in non-cognitive skills. Many of the earlier studies 
documenting how environmental factors contributed to disruptive behavior were published in medical journals, focused exclusively on boys (as this is the "at risk" group), and relied on very small sample sizes (Zahn-Waxler et al., 2008). In contrast, the core of our analysis is based on a large representative sample of boys and girls in the US that started kindergarten in 1998 and was followed until eighth grade.

We start by documenting the gender gap in non-cognitive skills among children, and how that gap evolves over the course of children's development. What is immediately remarkable is the size of these gender gaps. For example, by fifth grade, girls score about half a standard deviation below boys in teacher-reported externalizing problems and 0.45 of a standard deviation above boys in teacher-reported self-control. For comparison, the widely discussed gender gap in math is about 0.15 of a standard deviation in fifth grade and the (reverse) gender gap in reading is about 0.2 of a standard deviation in fifth grade. The gender gap in all non-cognitive skills widen in the early years of school.

While the data allows us to track the gender gap in many types of non-cognitive skills, our primary interest is in the set of non-cognitive skills that map into future educational and labor market outcomes. While we cannot directly analyze the effects of early non-cognitive skills on long-term outcomes given that the data stops in eighth grade, we show that externalizing behavior is a crucial determinant of school suspension. As discussed above, school suspension has been shown to directly matter for long-term educational outcomes. Therefore, our analysis will focus on explaining gender differences in externalizing behavior, which is based on the frequency with which a child argues, fights, gets angry, acts impulsively or disturbs ongoing activities. To complement our measure of externalizing behavior, we also attempt to explain gender differences in school suspension in eighth grade.

We test various socialization theories for the gender gap in behavioral and socio-emotional problems. We consider both home-based and school-based influences. We fail to uncover any compelling evidence that any of the school-based influences that we consider matter. In particular, while it has been argued that boys might be at a particular disadvantage in more regimented early schooling environments (because of the slower maturation of key brain areas), we find no systematic differences in the gender gap based on key features of the kindergarten 
environment. Also, we find no systematic differences in the gender gap based on age of kindergarten entry, whether we use the child's actual age or predicted age of entry. ${ }^{3}$ Moreover, there is no evidence of a gap in behavioral problems among children that are assigned to female teachers in their earlier years of schooling, or among children who are surrounded by more disruptive peers in their school or classroom.

In contrast, our analysis of the home environment uncovers more interesting patterns. Family structure is an important correlate of boys' behavioral deficit. Boys that are raised outside of a traditional family (with two biological parents present) fare especially poorly. For example, the gender gap in externalizing problems when the children are in fifth grade is nearly twice as large for children raised by single mothers compared to children raised in traditional families. By eighth grade, the gender gap in school suspension is close to 25 percentage points among children raised by single mothers, while only 10 percentage points among children in intact families. Boys raised by teenage mothers also appear to be much more likely to act out.

In the remainder of our analysis, we ask why boys raised by single mothers are at a higher risk of developing behavioral problems. First, it is possible that single mothers invest disproportionately less in their sons, or feel less warm toward them. Indeed, we show that single mothers seem relatively more emotionally distant from their sons and are also more likely to have reported spanking their sons. Complementary evidence from the American Time Use Survey (ATUS) confirms that single mothers spent relatively less time engaging in childcare related activities with their sons as compared to their daughters. Accounting for these endowment effects may explain a small part of the difference in the gender gap in externalizing behavior (in fifth grade) and grade suspension (in eighth grade) between children growing up in intact families and families headed by single mothers. Most important though are gender differences in the noncognitive returns to parental inputs. On average across children, broken families are associated with lower levels and lower quality of parental inputs; boys' non-cognitive development, unlike girls', appears extremely responsive to such inputs. Overall, our findings strongly suggest that

\footnotetext{
${ }^{3}$ Predicted age of kindergarten entry is computed based on the child's month of birth and the state cutoff age for kindergarten entry. Children in states where the cutoff is set by local school districts are excluded from the calculation. This measure tells us the age at which a child should enter kindergarten if he/she fully complied with the state cutoff based on his/her month of birth.
} 
boys' deficit in non-cognitive skills is not purely biological but instead subject to very strong environmental influences, particularly from the home.

\section{The Data}

The main data source for our analysis is The Early Childhood Longitudinal Study: Kindergarten Cohort (ECLS-K). ECLS-K is a longitudinal study of a nationally representative sample of over 20,000 children entering kindergarten in 1998. Information on these children has been gathered until they complete eighth grade. The full sample was interviewed in the fall and spring of kindergarten, spring of first grade, spring of third grade, spring of fifth grade and spring of eighth grade. About 1,000 different schools are included in the sample, and twenty children were interviewed per school. Information was collected about children's cognitive, social, emotional, and physical development from children, families, teachers, and schools. In addition, information about the children's home environment, educational practices at home, environment at school, curriculum, and teacher qualifications was also collected (National Center for Education Statistics, 2003). ${ }^{4}$

We use teacher-reported measures of five behavioral and social-emotional skills: externalizing problems, self-control, approaches to learning, interpersonal skills, and internalizing problems. These non-cognitive skill measures are adapted from the Social Skills Rating Scale, a widely used survey technique for detecting social and behavioral problems in the classroom (Gresham and Elliott, 1990). As Neidell and Waldfogel (2011) note, the ECLS-K non-cognitive measures appear to have relatively high "validity based on test-retest reliability, internal consistency, interrater reliability, and correlations with other, more advanced behavioral constructs (Elliott et al., 1988) and are considered the most comprehensive assessment that can be widely administered in large surveys such as the ECLS-K (Demaray et al., 1995)." Each of the non-cognitive measures averages answers to a series of questions that are rated on a scale from 1 (never) to 4 (very often). The measurement of externalizing problems is based on five questions assessing the frequency with which a child argues, fights, gets angry, acts impulsively, and disturbs ongoing activities. The measurement of self-control is based on four questions assessing the child's ability to control behavior by respecting the property rights of others, controlling his or her temper,

\footnotetext{
${ }^{4}$ See http://nces.ed.gov/ecls for details.
} 
accepting peer ideas for group activities, and responding appropriately to pressure from peers. "Approaches to learning" measures behaviors that affect the ease with which children can benefit from the learning environment; it averages six items that rate child's attentiveness, task persistence, eagerness to learn, learning independence, flexibility and organization. Interpersonal skills rate the child's skill in forming and maintaining friendships, getting along with people who are different, comforting or helping other children, expressing feelings, ideas and opinions in positive ways, and showing sensitivity to the feelings of others. Finally, internalizing problems is based on four questions that ask about the apparent presence of anxiety, loneliness, low selfesteem and sadness with the child. Appendix Table A1 provides further details of these measures. We complement these non-cognitive variables with a measure of school suspension: a dummy variable that equals 1 if the parent reports that the child has experienced an in or out of school suspension in eighth grade. The sample is restricted to children who have non-missing data on key background characteristics such as gender, race, age at assessment, region, urbanicity, sibling composition, family structure, mother's age at first birth and family SES in the fall of kindergarten. ${ }^{5}$ As there is substantial attrition in the ECLS-K panel, we further restrict the sample to children who have valid teacher ratings of externalizing behavior in the fall of kindergarten and grade 5 as well as the parental reported measure of school suspension in grade 8. ${ }^{6}$ In all our specifications, we weight the observations using the eighth grade panel weights provided in ECLS-K. ${ }^{7}$

Summary statistics for these non-cognitive traits are presented in Table 2 . We convert each of the teacher ratings into a standardized normal with mean zero and standard deviation one in the weighted sample after imposing the sample restrictions. Table 2 reports raw mean girl-boy

\footnotetext{
${ }^{5}$ While we have measures of some of these background characteristics at multiple points in time (e.g. family structure and family SES), throughout the paper, we use the Fall-K measures to ensure consistency and to limit potential endogeneity concerns. Results are generally not sensitive to whether we use the Fall-K measures or the year-specific measures.

${ }^{6}$ We have also replicated the results using the sample of children with valid information in each wave separately the results are similar to those we obtain from imposing the sample restriction. These results are available from the authors upon request.

${ }^{7}$ Because of the complex sampling procedure utilized by ECLS-K, different weights are suggested depending on the set of variables used. We use the eighth grade parent panel weight (C1_7FP0). This weight is recommended to be used for the analysis of parent interview data from six rounds of data collection (fall-kindergarten, springkindergarten, spring-first grade, spring-third grade, spring-fifth grade and spring-eighth grade), alone or in combination with (a) child assessment data from any of these six rounds (b) data from any of the six waves of the teacher questionnaire (teacher-level or child-level) (ECLS-K Combined Eighth Grade and K-8 User's Manual (2009)).
} 
differences in these non-cognitive traits. We present these differences for the fall of kindergarten (the first time they are measured), the spring of kindergarten, first, third and fifth grade (the last time they are measured). Girls score better on each of the five non-cognitive measures at all ages and these gaps appear to widen as kids age.

The average boy "acts out" between 0.44 (kindergarten) and 0.52 (fifth grade) standard deviations more than the average girl on the externalizing problem index, and he scores between 0.36 and 0.45 standard deviations below the average girl in terms of self-control, or selfregulation. Similar gaps exist for "approaches to learning" and "interpersonal skills." The gender gap is smallest for internalizing problems, a trait that captures anxiety, loneliness, low selfesteem and sadness. Finally, girls are less likely to have repeated a grade and to have been suspended from school in eighth grade. Nearly one out of four boys experienced at least one school suspension in eighth grade, while only one out of ten girls did.

The remaining rows of Table 2 report the well-known gender gaps in both math and reading skills. ${ }^{8}$ Girls outperform boys with respect to reading but lag behind in math; while the (reverse) gender gap in reading is already present in kindergarten, the gender gap in math only emerges in first grade. ${ }^{9}$ What is remarkable is how large the gender gaps in non-cognitive skills are compared to the gender gaps in reading and math scores. The (reverse) gender in reading ranges between 0.2 and 0.27 of a standard deviation while the gender gap in math ranges between 0 and 0.18 of a standard deviation; this is in contrast to the gender gaps in non-cognitive skills which are all closer to 0.5 standard deviations (with the exception of internalizing problems).

While we do not, as indicated above, directly use parental ratings of non-cognitive skills in our analysis below, Appendix Table A3 report gender gaps for those ratings as well. ${ }^{10}$ The questions asked to parents do not perfectly match those asked to teachers, but the patterns we observe in Appendix Table A3 are qualitatively similar to those in Table 2, even though the magnitude of the parent-reported gender gaps in non-cognitive skills are smaller. Parents rate daughters as

\footnotetext{
${ }^{8}$ The reading and math test scores reported are item response theory (IRT) scores provided in ECLS-K, which we convert into a standardized normal with mean zero and standard deviation one in the weighted sample after imposing the sample restrictions.

${ }^{9}$ See Fryer and Levitt (2010) for an analysis of the gender gap in math scores using the ECLS-K data.

${ }^{10}$ Ideally, we would have liked to use the parent reported measures of non-cognitive skills in the main analysis as well; unfortunately, this data was only collected in kindergarten and first grade.
} 
relatively less likely to act impulsively, which maps into the teacher-reported gender gap in both externalizing and self-control problems. Girls are also more likely to exert self-control and score higher than boys when rated by their parents on their "approaches to learning" and social skills. Consistent with the small teacher-reported gender gap in internalizing problems, parents do not perceive any systematic differences in sadness or loneliness between their sons and daughters.

Has the gender gap in non-cognitive skills changed over time? This is a difficult question to address because the measurement of non-cognitive skills is either absent from many earlier datasets or, if present, are not consistently measured across datasets. However, it is possible to track school suspension rates among various cohorts of eighth to tenth graders by combining information from various nationally representative education datasets such as High School and Beyond (HSB-1980), NELS, Educational Longitudinal Survey (ELS-2002) and ECLS-K. We report this analysis in Table 3. We can compare school suspension among tenth graders in 1980 (HSB), tenth graders in 1990 (NELS), tenth graders in 2002 (ELS) and eighth graders in 2006 (ECLS-K). Among girls, the likelihood of suspension goes from 8.6 percent (1980) to 11.5 percent (1990) to 12.7 percent (2002) to 11 percent (2006). Among boys, there is a steadier trend up: from 15.7 percent (1980) to 18.8 percent (1990) to 20.7 percent (2002) to 24 percent (2006). These two trends translate into a growing gender gap in school suspension over the last quarter century. There are two possible explanations for this: either boys are indeed experiencing more behavioral problems today than they did a quarter century ago or schools have become more likely to sanction such unruly behavior with suspension. In any case, the evidence in Table 3 suggests that understanding the sources of boys' behavioral and socio-emotional problems is if anything an even more pressing issue today than it was in the past.

One might expect that not all of the early childhood non-cognitive skills discussed above feed the same way into future educational and labor market outcomes. Unfortunately, the ECLS-K data does not go beyond eighth grade and it is therefore impossible to directly relate educational achievement or earnings to these various early childhood non-cognitive measures. Yet, we can relate them to school suspension in eighth grade, which has been shown to be predictive of college attendance and college completion (see Table 1). We do this in Table 4. Specifically, we regress the likelihood of any school suspension in eighth grade on the five teacher-reported noncognitive skills discussed above. We also include reading and math test scores. In column 1, we 
include a measure of these cognitive and non-cognitive skills in fifth grade; in column 2, we include the comparable skills as measured in the fall of kindergarten. Each regression also includes a female dummy, race dummies (Black, Hispanic, Asian, other), age at assessment at Fall-K, age-squared, birth weight, number of older brothers, number of younger brothers, number of older sisters, number of younger sisters and dummies for region and urbanicity.

By far the strongest and most robust predictor of eighth grade suspension is externalizing behavior. A one standard deviation increase in externalizing problems in fifth grade (fall kindergarten) increases the likelihood of an eighth grade school suspension by 9 (5) percentage points. We see some influence of fifth grade interpersonal skills, but not kindergarten interpersonal skills; we also see some influence of self-control when measured in kindergarten, but not when measured in fifth grade. Finally, there are no statistically significant influences of fifth grade math and reading scores on the likelihood of eighth grade suspension; yet a higher math test score in fall kindergarten appears to be negatively correlated to eighth grade suspension, everything else held constant. For comparison, in the final four columns of Table 4, we look at the relationship between the different measures of teacher reported non-cognitive skills and reading and math test scores in grade 8 . In contrast to the results for grade suspension, a kid's "approach to learning" appears to be the most important predictor of his or her future cognitive test scores. Internalizing behavior also seems to matter, although to a much smaller degree. Overall, the evidence in Table 4 motivates our focus in most of the analysis below on the gender gap in externalizing problems, or in the tendency to "act out."

\section{What Drives the Gender Gap in Non-Cognitive Skills?}

In an attempt to understand the forces driving the gender gap in non-cognitive skills, we examine how the gap varies across various sub-samples of the data. To the extent that the magnitude of the gap varies along observable dimensions, this may shed light on the sources of the gender gap. For this analysis, we restrict ourselves to the following measures of non-cognitive skills: externalizing behavior (both in Fall-K and fifth grade) and the likelihood of suspension in eighth grade. 


\section{The Home Environment}

Summary statistics by gender for the home environment variables and child's background characteristics that we exploit in the analysis are presented in Table 5 and Appendix Table A4, respectively. There are only very small differences in family structure, parental SES and sibling composition across genders; consistent with the expectation that gender is essentially randomly assigned across families. ${ }^{11}$ In other words, it is not the case that boys are disproportionately likely to grow up in disadvantaged families, and thus differences in family background cannot be a direct factor in explaining the overall gender gap in non-cognitive skills. We also see no systematic differences across gender in region of residence, or rate of urban living (see Appendix Table A4). ${ }^{12}$

We do however observe some differences with respect to the level of inputs these families are investing in their children. For most of the analysis that follows, we measure these parental inputs in kindergarten. Parents are significantly more likely to read to their girls, and there are generally more books around girls. They are also more likely to take their girls to a concert and to sign them up for some extra-curricular activity. Overall, the parental input composite that averages these various components of parental investments (see Appendix Table A2 for details) shows an advantage for girls. Parents are slightly more likely to have reported spanking their boys as compared to their girls in the past week (in kindergarten), although this difference is not statistically significant. Finally, there is a small but statistically significant gender gap in the emotional distance composite we constructed based on questions relating to how close parents feel to their kindergarteners (see Appendix Table A2). In the kindergarten survey, parents of daughters are less likely to report being too busy to play with their child relative to parents of sons; they also feel more loved by their daughters than their sons.

\footnotetext{
${ }^{11}$ There is some evidence that boys and girls may be raised in different family environments due to a small degree of son preference in the US. For example, Dahl and Moretti (2008) find that girls are more likely to have absent fathers and tend to have more siblings. Similar evidence is also found by Fortin, Oreopoulos and Phipps (2011). The gender differences are generally quite small and our failure to find gender differences in the family environment in our sample is likely due to the relatively small sample size in ECLS-K.

${ }^{12}$ We find some small gender differences in family SES. In this sample, boys are slightly more likely to be in the lowest two SES quintiles as compared to girls. However, the magnitude of these differences are very small and are only marginally significant at the $10 \%$ level.
} 
For completeness, we also report the summary measures of home inputs, disciplinary style and emotional distance as an average from kindergarten to third grade in the lower rows of Table 5. Similar patterns emerge - on average, girls receive slightly higher levels of parental inputs and they are somewhat less likely to be spanked; also, parents feel emotionally closer to a daughter than to a son. Finally, we also see a small but significant gender gap in parental expectations about college attendance. While close to 80 percent of parents expect their female kindergartener to eventually attend college, only 77 percent of parents expect their male kindergartener to do so. This gender gap in parental expectations about college attendance grows about 10 percentage points by fifth grade.

Given the minimal differences in the home environment we observe between boys and girls, it is not surprising that directly controlling for those variables has a minimal effect on the gender gap. This is demonstrated in Table 6. The first panel of Table 6 presents the estimated gender gap (female dummy) in externalizing behavior in fall of kindergarten (column 1), externalizing behavior in fifth grade (column 2), and school suspension in eighth grade (column 3), controlling for race dummies (Black, Hispanic, Asian, other), age at assessment at Fall-K, age-squared, birth weight, number of older brothers, number of younger brothers, number of older sisters, number of younger sisters and dummies for region and urbanicity. The second panel (Panel B) replicates the same analysis but restricts the sample to those children for which we have non-missing information on family background and other parental inputs. Panel C adds controls for family type and socio-economic background, all measured at fall-kindergarten: dummies for family structure (single mother, both biological parents and other family structures), a dummy for teen motherhood and five dummy variables indicating the family's SES quintiles. As expected based on the evidence in Table 5, adding these controls pretty much leaves the estimated gender gaps in externalizing behavior and school suspension unaffected. Panel D further controls for the parental input measures presented in Table 5, again all measured at fall-kindergarten: the HOME index, the emotional supportiveness index and parent's disciplinary style. These additional controls do contribute to reducing the estimated gender gap on both externalizing behavior in fifth grade and suspension in eighth grade, but this effect in quantitatively very small. The gender gap in externalizing behavior in fifth grade goes from -0.50 to -0.48 ; the gender gap in school suspension goes from -0.15 to -0.14 . 
Hence, to summarize Table 5 and Table 6, we see little systematic evidence of differences in family background or parental inputs between boys and girls that would directly contribute to boys' conduct problems. Perhaps not surprisingly, to a first degree approximation, boys and girls are raised in fairly similar families and receive fairly similar parental inputs, at least to the extent that these variables are adequately captured in the data. Yet, similar backgrounds for boys and girls may hide important home influences for the gender gap in non-cognitive development. For example, some have raised the possibility that boys raised by single mothers are at a particular disadvantage in terms of behavioral development. This could arise, for example, because single mothers have a preference for girls and disproportionately invest in them. ${ }^{13}$ Another possibility is that even if single mothers invest equally in the development of their boys and girls, maternal input could be a poorer substitute for the lack of paternal inputs when it comes to raising a boy. Similar arguments may apply to young and immature mothers who could be less invested in their sons or less effective at controlling their behavior. Another possible argument is that boys, because they are born at a greater risk of developing behavioral and socio-emotional problems (as suggested by the medical literature discussed in the introduction), benefit more from the greater average level of inputs that is typically provided in more educated, richer or intact families. ${ }^{14}$ In other words, boys' non-cognitive development may be more responsive to parental inputs as compared to girls'. Hence, while we may not observe any differences in the home environment between boys and girls on average, this does not necessarily imply that the home environment is not a contributing factor to the gender gap in non-cognitive skills.

To explore this issue, Table 7 focuses on variation in the gender gap in non-cognitive skills across family types and other key features of the home environment. Each row corresponds to a different subset of the data and each cell corresponds to a different regression. Reported in each cell is the estimated female dummy based on a separate subsample of the data. Background covariates include race dummies, age at assessment at Fall-K, age-squared, birth weight, number of older brothers, number of younger brothers, number of older sisters, number of younger sisters and dummies for region and urbanicity. We report robust standard errors in brackets. Column 1

\footnotetext{
${ }^{13}$ For example, Lundberg, Pabilonia, and Ward-Batts (2007) find that single moms spend more time with daughters relative to sons than married moms. We report similar evidence in Section 4.

${ }^{14}$ Guryan et al (2008) show that college-educated and non-college educated parents allocate different amounts of time to their children, with highly educated parents devoting much more time to their kids compared to lower educated parents.
} 
reports the estimated gender gap in externalizing behavior in Fall-K, column 2 reports the estimated gender gap in externalizing behavior in fifth grade and column 3 reports the estimated gender gap in the likelihood of any suspension during eighth grade. The various aspects of the home environment are all measured in the fall of kindergarten.

Panel A focuses on family structure. We compare the gender gap in non-cognitive skills across three family structures: intact families (two biological parents), single mothers and other family structures. $^{15}$ Looking across family structures in column (1), the size of the gender gap in externalizing behavior in the fall of kindergarten appears relatively similar across intact and nonintact families. This is confirmed by a formal test of the equality of the gaps, which yields a pvalue of 0.269 . Strikingly, differential patterns by family structure appear to emerge in Grade 5 and Grade 8 for externalizing behavior and grade suspension, respectively. In Grade 5 (column 2), the gender gap in externalizing behavior more than doubles among children in single mother families and remains constant among children in intact families and those in the "other" family structure. The gender gaps in externalizing behavior in fifth grade and suspension in grade eight (column 3) is smallest in intact families. All other family structures appear detrimental to boys. For example, the gender gap in externalizing behavior in fifth grade goes from -0.41 standard deviations among children in intact families, to -0.77 standard deviations among children raised by a single mother. Also, while the gender gap in eighth grade suspension is only about -0.10 among children raised by two biological parents, this gap grows to -0.25 and -0.27 for boys raised by a single mother or in other family arrangements, respectively. The p-values reported at the bottom of panel $\mathrm{A}$ in columns 2 and 3 strongly reject that the gender gaps are equal across family structures.

Of course, family structure correlates strongly with other family background characteristics. One obvious candidate is the family's socio-economic status - for example, the share of children raised by a single mother is about 40 percent in the lowest SES quintile while that share is only 9 percent in the highest SES quintile. Similarly, only about 44 percent of children in the lowest SES quintile are raised by two biological parents, while more than 80 percent are in the highest SES quintile. In other words, what might be interpreted as the (negative) influence of a missing

\footnotetext{
${ }^{15}$ The "other" family structure includes a range of family types such as children with a biological father only, one biological parent and one non-biological parent, adoptive parents, related guardians and non-related guardians.
} 
biological father on boys' non-cognitive development might in fact reflect differential returns to other socio-economic inputs by gender. We directly examine the potential role of socioeconomic background in the remaining subsamples presented in Panel B of Table 7. We see some evidence of a negative socio-economic gradient in the gender gap in non-cognitive skills in the later grades. For example, the gender gap in externalizing behavior in fifth grade is about $0.63,-0.53,-0.53,-0.42$ and -0.35 among children in the lowest, second, third, fourth and fifth SES quintiles, respectively. Similar to the comparison across family structures, these differential patterns by family SES are not evident in the fall of kindergarten.

Panel C of Table 7 compares the gender gap in non-cognitive skills based on mother's age at first birth. This is another variable that is likely to be strongly correlated to family structure; indeed, we find that about 47 percent of children raised by a single mother are also children of a mother who was less than 20 years old at the time of a first birth; in contrast only 19 percent of children in intact families have teenage mothers. Panel C confirms that mother's age at first birth is another strong correlate of the gender gap in non-cognitive skills. For example, the gender gap in externalizing behavior in fifth grade is -0.78 among children raised by mothers who first experienced motherhood in their teens; it is only -0.40 among children raised by mothers that did not experience motherhood until their twenties. The equivalent figures for the gender gap in eighth grade school suspension are -0.26 and -0.11 , respectively.

Figure 1 provides some graphical evidence on externalizing problems among boys and girls based on these three family types. We include here all the years in which externalizing behavior is measured in ECLS-K. Panel A contrasts single mothers to intact families; Panel B contrasts families in the lower two and higher three SES quintiles; finally, Panel C contrasts families with mothers that first gave birth in their teens and those that first gave birth in their twenties or later. While females have a much lower incidence of externalizing patterns in all grades, in each panel, the size of the gender gap is similar across family types as kids enter kindergarten. The only group that appears to "trend" negatively over time is that of boys raised in "lower quality" families (single mothers, lower SES, teenage mothers). Across the other three sets of children, the gaps in externalizing problems remain stable over time. These figures, in combination with the analysis in Table 7, are consistent with the idea that some features of the home environment are particularly detrimental to boys' non-cognitive development. Particularly striking is the 
widening deficit we observe for boys raised in disadvantaged families over time. In Section 4, we will explore what drives these relationships. In particular, we will focus on why boys raised by single mothers seem to be at such a disadvantage.

\section{The School Environment}

Both the home and school environments affect children's early socialization. Therefore, we now turn our attention to possible influences of the early school environment on the incidence of behavior problems among boys. In particular, some psychologists have discussed the possibility that boys are at risk of developing behavioral problems because schools expect too much from them from a very young age, when their brain maturity is not quite on par with that of girls. Parents might be somewhat aware of this, or at least believe in the relevance of this argument in that, as others have pointed out before, they are more likely to hold their sons back when it comes to starting school (a pattern we confirm below). In a popular but controversial book, Leonard Sax (2007) argues that many boys develop negative attitudes toward school and exhibit conduct problems because of challenging experiences in kindergarten; he further argues that recent changes in early education are placing more demands on children, with the unintended consequence of disadvantaging many boys. Others have pointed out that the early school environment might be particularly problematic for boys because of the overwhelming share of female teachers, who may either discriminate against boys or be less able to adapt their teaching or disciplining styles to the specific needs of boys (Dee, 2006). Finally, it is possible that boys' conduct is particularly responsive to negative peer effects: boys might be particularly at risk of developing behavioral problems if placed in a classroom with more disruptive kids.

We assess the relevance of these various theories by comparing the gender gap in externalizing behavior across these features of the kindergarten and early school environments. Tables 8 and 9 are structured in the same way as Tables 5 and 7, respectively. In Table 8, we compare average characteristics of the early school environment by gender. There is little difference in the early school environment by gender. Parents are slightly more likely to hold their sons back but the difference is not very large. The average girl is about 0.25 months younger than the average boy when she starts kindergarten. By and large, it appears boys and girls start their education at schools that are very similar in terms of their academic demands, teaching style and teacher 
gender. We also see no differences in average peer characteristics, in particular the share of peers with externalizing problems.

Not surprisingly, simply controlling for these school-related variables does little to the estimated gender gap in non-cognitive skills. This is shown in the last panel of Table 6, where we present the estimated gender gap in non-cognitive skills after controlling for both the home environment and the variables reported in Table 8. The estimated gender gaps in externalizing problems in kindergarten, externalizing problems in fifth grade and the likelihood of school suspension in eighth grade are essentially unchanged after controlling for these features of the early school environment. ${ }^{16}$

Table 9 assesses whether there are any systematic differences in the gender gap in non-cognitive skills based on these features of the early school environment. Again, while these elements of the early childhood environment are essentially balanced across gender, it is still possible that boys are particularly at risk of developing conduct problems in some early school settings.

We first compare the gender gap based on the age of entry in kindergarten. Of course, this is a potentially endogenous variable as parents may be more likely to hold their boys back if they judge them to be less ready for school, which is likely to be related to their behavioral maturity. To get around this, we also present a breakdown of the gender gap in non-cognitive skills by predicted age of kindergarten entry. The child's predicted age of kindergarten entry is computed based on the child's month of birth and the state cutoff age for kindergarten entry. Children in states where the cutoff is set by local school districts are excluded from the calculation. This measure tells us the age at which a child should enter kindergarten if he/she fully complied with the state cutoff based on his/her month of birth. ${ }^{17}$ We compare the gender gap in externalizing behavior and grade suspension across two groups of children based on whether their actual kindergarten entry age (Panel A) or predicted entry age (Panel B) was above or below the

\footnotetext{
${ }^{16}$ Due to the large number of missing observations for some of the school environment variables, in the bottom panel of Table 6, we use all the observations (with non-missing values for parental input measures) and include indicator variables for children with missing values on each of the school environment variables.

${ }^{17}$ Information on state cut-offs are obtained from Elder and Lubotsky (2009).
} 
median age of kindergarten entry among all the children in the sample. ${ }^{18}$ The gender gaps in externalizing behavior and grade suspension are broadly similar across the two groups of children regardless of whether we use the child's actual or predicted age. This suggests that kindergarten entry age has a limited influence on the gender gap in non-cognitive skills.

Panel C compares the gender gap in non-cognitive skills between public and private kindergartens. Boys' non-cognitive deficit appears to be somewhat larger in a public school environment. Of course, this raises the question of the extent to which this has to do with the school or the home environment as we expect children from more disadvantaged families to be more likely to attend public schools. In regressions not reported here, we looked at the public/private relative gender gap separately across the three family structures we used in Table 7. The patterns we observe are consistent with boys experiencing relatively more conduct problems in public schools across all family structures.

The next rows of Table 9 focus on specific features of the kindergarten environment. We are particularly interested in comparing how boys are faring behaviorally in more and less regulated kindergarten environments. Again, one of the arguments that has been brought forward by "pop psychologists" and relayed in the media is that boys might be unable to cope in kindergartens that force them to pay attention for long periods of time and demand more regulated learning, as their brain might not be mature enough to deal with such structured learning at an early age. To proxy for this, we separate kindergartens based on whether they (a) put above or below median emphasis on reading and math in the full sample, (b) put above or below median emphasis on homework, (c) put above or below median emphasis on achievement and behavior, (d) how much time they spent on physical activity and (e) how much time they spent on recess. We see strikingly little difference in the gender gap in non-cognitive skills across these dimensions of how regulated the kindergarten environment is. Similarly, when we separate kindergartens based on whether or not they have a formal retention policy (with the view that a formal retention policy proxies for a more regulated environment), we see little systematic differences in the gender gap. Not surprisingly, a breakdown of the data based on a summary index of how

\footnotetext{
${ }^{18}$ We have also estimated specifications where we compare children based on whether their actual or predicted kindergarten entrance age is above or below the median kindergarten entrance age in their state of residence. The results are very similar and are available upon request.
} 
regulated the kindergarten is (which loads positively on emphasis on math and reading, emphasis on homework and having a formal retention policy) also fails to show large differences. ${ }^{19}$ In contrast to the popular claims discussed above, boys appear to be doing relatively better behaviorally and face a smaller risk of school suspension in higher grades when placed in a more regulated kindergarten environment. The final school characteristic we consider in Table 9 is peer quality. In particular, we compute the gender gap in externalizing behavior and school suspension for children whose kindergarten classroom or school scored above or below the median in terms of the average level of externalizing problems. ${ }^{20}$ Again, we fail to find any evidence that boys are particularly at risk of behavioral problems if surrounded by more disruptive peers in early school settings.

A more regulated kindergarten environment might be only deleterious to boys that enter such an environment at a very young age. In Appendix Table A5, we therefore compare the gender gap in more and less regulated kindergarten environments separately based on the age of the child's entry into kindergarten (above and below median) as well as based on their predicted age of entry (above and below median). Again, we see none of the patterns we would have expected. In particular, there is no sign that the gender gap in non-cognitive skills is larger among children who start attending more regulated kindergartens at an early age whether we use actual age or predicted age. Overall, the patterns we observe in Appendix Table A5 offer little support for the view that learning demands placed on kindergarteners are responsible for boys' behavioral and socio-emotional deficit compared to girls.

Finally, Table 10 considers another feature of the kindergarten and early school environment: teacher gender. Indeed, as we discussed above, some have also raised the possibility that kindergarten teachers, a large share of them being women, are simply less able or willing to attend to the behavioral and emotional needs of boys. This might be particularly true if girls account for a large share of the kindergarten classroom. Such a possibility might be a further concern as our measures of non-cognitive development are based on teachers' evaluation. So,

\footnotetext{
${ }^{19} \mathrm{We}$ find some evidence that kindergartens that spend more time on recess is associated with smaller gender gaps in externalizing behavior in grade 5, however, this is only marginally significant at the $10 \%$ level and we do not see similar patterns for suspension in grade 8.

${ }^{20} \mathrm{We}$ exclude the focal child when computing the average externalizing behavior of a child's peers in the classroom or school.
} 
two things are possible: female teachers do a poor job at emotionally guiding boys (e.g. real effects on boy's behavior), or female teachers are unduly harsh in judging boys (e.g. the gender gap in non-cognitive skills we observe is in part the result of biased teacher assessments).

We first compare the gender gap in non-cognitive skills based on the gender of the kindergarten teacher. Note that the sample of children with a male kindergarten teacher is very small and therefore standard errors are quite large. The gender gap in externalizing behavior in Fall-K and school suspension in grade 8 appears smaller among children with a male kindergarten teacher relative to those with a female teacher, although these differences are not significant at conventional levels. Nevertheless, we do not find systematic differences in externalizing behavior in grade 5. Turning to the gender of the teacher in grade 5, we do not find any evidence of differences in externalizing behaviors both in fall-K and grade 5. The gender gap is school suspension in grade 8 is somewhat lower among children with male teachers in grade 5 . If we separate children based on whether all their teachers from kindergarten to grade 5 are female or whether they had at least one male teacher over those grades, we find no systematic difference in the gender gaps. In these tabulations, if anything, the gender gaps appear to be larger among those with at least one male teacher from kindergarten to grade 5 relative to those with all female teachers.

In the remaining rows of Table 10, we further breakdown the sample of children with all female teachers from kindergarten to grade 5 and those with at least one male teacher based on whether they attended classrooms with above or below median shares of girls in the classroom. Again, it is hard to discern any systematic patterns. In particular, boys with all female teachers in classrooms with a larger fraction of female classmates do not appear any more likely to be disruptive or to face school suspension in the later grades.

Overall, the evidence in Tables 9 and 10 is in sharp contrast to the evidence in Table 7. While we find large differences in the gender gap in non-cognitive skills across key features of the home environment, we do not observe systematic patterns across features of the kindergarten environment. These findings motivate the deeper investigation into the parent-children dynamics that we perform in the remaining sections of the paper. 
Finally, given that we observe multiple children in the same school, we are able to isolate the home environment from the school environment more precisely. Specifically, we can replicate the analysis in Table 7 by further controlling for school (kindergarten) fixed effects. These estimates are reported in Appendix Table A6. Although the size of the gender gaps is smaller in some cases, the qualitative results of Table 7 remain largely unchanged.

\section{Why Are Boys Raised by Single Mothers Particularly at Risk?}

One of most striking patterns we have documented so far relates to the especially large gender gap in non-cognitive skills in non-intact families that emerge by middle school. Why is this happening? One possibility is that boys raised without a biological father receive especially low levels of parental inputs, parental warmth and emotional supportiveness, or parental expectations, compared to girls raised in similar families. While we already established in Table 5 that there are only small differences in the home environment between boys and girls, it is still possible that this aggregate analysis hides more systematic differences when we hold family structure constant.

In Appendix Table A7, we therefore reproduce the summary statistics reported in Table 5 separately by family structure (intact families, single mothers, other). Again, we prefer to measure these parental inputs in kindergarten to limit reverse causality concerns; for completeness though, we also report averages over the kindergarten to third grade interviews. When it comes to the home environment composite, which loads on parental inputs such as reading to children or engaging children in extra-curricular activities, we find no evidence that single mothers invest disproportionately more in their girls. As noted in Table 5, daughters tend to receive slightly more inputs than sons, but this is true both in intact families and in families headed by a single mother.

However, we do observe somewhat larger gender gaps in emotional supportiveness and disciplining style in families headed by single mothers. Specifically, while parents in both intact and broken families report more emotional distance with their sons as compared to their daughters, the gap is larger in broken families. While there is no evidence of a gender difference in the likelihood that parents in intact families spanked their child, boys in broken families are about 13 percentage points more likely to have been spanked in the last week as compared to 
girls. We see somewhat similar patterns when we measure average parental inputs from kindergarten and third grade. The most robust difference across family structures appears to be with respect to emotional distance: single mothers appear especially distant from their sons. ${ }^{21}$ One concern with these results is that the incidence of spanking and the lack of emotional support could be a consequence of the child's misbehavior. Note, however, that both these measures were asked in Fall-K and we did not find any evidence of gender differences in externalizing behavior across family structures in the fall of kindergarten. The differences only emerge in the later grades. Therefore, it is unlikely that the gender differences in parental inputs across family structures are simply a response to the child's behavior in Fall-K. We will address this concern more formally by including the child's prior externalizing behavior in Fall-K as a control in some of our later specifications.

Complementary evidence of a larger gender gap in investment in families headed by a single mother can be found in other surveys. Using data from the 2003-2005 American Time Use Survey (ATUS) and the Child Development Supplement of the Panel Study of Income Dynamics (PSID-CDS), Lundberg, Pabilonia and Ward-Watts (2007) find that single mothers spend more time with daughters relative to sons compared to married mothers. In Appendix Table A8, we extend their analysis of the ATUS data to the longer time period that is now available (20032010). We restrict the sample to female respondents with at least one child under 5 years old in their roster. We categorize respondents based on whether or not they are married, as well as based on whether or not they live in a couple. For each activity listed in the activity file, we merge in information about the identity of the children that were present while this activity was performed. This allows us to construct, for each child, the time spent by the respondent (either mother or father) with that child in childcare-related activities, which we label "total child care" and convert into hours per week. ${ }^{22}$ Using the child as the unit of observation, we then regress total childcare time on a dummy for son, as well as dummies for child age, the number of children under 18 in the same roster and a dummy that equals 1 if the time use survey was conducted over a weekend. We are mainly interested in comparing the estimated gender gap in

\footnotetext{
${ }^{21}$ Of course, one might be particularly concerned when we use input over this longer time period that the child's misbehavior is the cause rather than the consequence of this relative lack of emotional support. Therefore, for most of the analysis, we use the parental input measures in Fall-K to minimize endogeneity concerns.

${ }^{22}$ We adopt Guryan, Hurst and Kearney (2008)'s definition of "total child care."
} 
childcare time across children living in different family structures. We report our findings separately for all children under the age of five, as well as for the subset of children under the age of three.

The patterns we observe confirm the earlier findings of Lundberg, Pabilonia and Ward-Watts (2007) and are consistent with the patterns in Appendix Table A7. Mothers in stable family structures (married mothers and mothers living in a couple) do not appear to spend statistically less time with their sons than they do with their daughters. In contrast, single mothers spend between 1.2 and 1.4 hours less per week with their sons than with their daughters in the sample of kids under five (the mean weekly hours of total childcare by mothers in that sample is 17.8). This gender gap in investment is even more pronounced in the subsample of children under three (where endogeneity concerns about parent time allocation are more limited), with single mothers spending between 2.1 and 2.3 fewer hours of total childcare with their sons (the mean weekly hours of total childcare by mothers in that sample is 19.4). In summary, the evidence in Appendix Tables A7 and A8 suggest that boys raised by single mothers might be particularly disadvantaged as they receive lower levels of parental inputs compared to all other groups of children in the sample.

But how much of the disparity in the gender gap in non-cognitive skills across family structures can these differences in the gender gap in parental inputs explain? Table 11 addresses this question. Specifically, columns 1 and 4 report, by family structure, the estimated female dummy in a regression of externalizing behavior in fifth grade where we only control for background variables (race dummies, age at assessment at Fall-K, age-squared, birth weight, number of older brothers, number of younger brothers, number of older sisters, number of younger sisters and number of dummies for region and urbanicity). These gaps are very similar to the raw gaps reported in Table $7 .^{23}$ Among children raised by single mothers, boys score about 0.77 of a standard deviation below girls in terms of externalizing behavior in fifth grade; they are about 0.25 percentage points more likely than girls to be suspended in eighth grade (see columns 1 and 7). The equivalent figures among children raised in intact families are 0.40 and 0.10 respectively (see columns 4 and 10). Columns 2, 5, 8 and 11 show how this estimated gender gap by family

\footnotetext{
${ }^{23}$ The slight difference in the coefficient and number of observations is attributable to the fact that in Table 11, the sample is restricted to children with no missing values for the parental input measures.
} 
structure is affected by controlling for the parental inputs listed in Appendix Table A7. Among children raised by single mothers, the gap in externalizing behavior goes down to 0.71 (column 2) while the gap in school suspension goes down to 0.23 (column 8). Not surprisingly, given our findings in Appendix Table A7, controlling for parental inputs has a limited impact on the estimated gender gaps in intact families (column 5 and 11): the gap in externalizing behavior in fifth grade goes down to 0.39 and the gap in school suspension remains at approximately 0.10 . Hence what started as a $(0.77-0.40) / 0.40=93$ percent larger gap in externalizing behavior among children raised by single mothers has been reduced to a $(0.71-0.39) / 0.39=82$ percent larger gap. Similarly, the original $(0.25-0.10) / 0.10=150$ percent larger gap in suspension has been reduced to a $(0.23-0.10) / 0.10=130$ percent larger gap. In other words, our results are consistent with the view that a small but non-trivial share of boys' higher rate of behavioral problems in single mother families might be due to differences in inputs by child gender. Nevertheless, these findings remain speculative due to the relatively large standard errors of the estimates.

Next, we explore the possibility that the remaining (large) unexplained difference in the gender gap by family structure may be due to gender differences in the returns to parental inputs and parental quality. We begin by exploring the relationship between non-cognitive development and parental inputs across both single mom and intact families separately by gender. Columns 1 (girls) and 2 (boys) of Tables 12A and 12B include three measures of parental inputs - the HOME index, parental warmth index and whether the child was spanked last week. The most striking finding is that there is a stronger relationship between parental inputs (measured in kindergarten) and further non-cognitive development for boys than there is for girls. For example, for boys, above median levels of the HOME index and parental warmth index decrease the likelihood of externalizing behavior in fifth grade by 0.08 and 0.2 standard deviations, respectively. In contrast, we see virtually no relationship between these input variables and girls' externalizing problems in fifth grade. The reliance on harsher disciplining in kindergarten feeds into more conduct problems and a higher likelihood of school suspension in eighth grade for boys; again, in contrast, there is a much weaker relationship between spanking and non-cognitive problems for girls. These findings are particularly relevant in that, as we saw in Appendix Table A7, intact families score on average (across children) higher than broken families on both the HOME index and the warmth index. 
Columns 3 and 4 further control for family SES and teenage motherhood. We view these two variables as additional proxies for the quantity and quality of parental inputs. Family SES and teenage motherhood appear to have a larger effect on boys' non-cognitive development compared to girls'. Particularly striking is the effect of teenage motherhood - holding all else constant, boys raised by teenage mothers have externalizing behavior scores (suspension rates) that are 0.55 standard deviations ( 21 percentage points) higher than boys raised by a non-teenage mother; the equivalent figure for girls is about 0.05 standard deviations ( 5 percentage points). The fact that boys do especially poorly behaviorally when raised by teenage mothers is particularly relevant to us given the lower share of such mothers in intact families.

The remainder of the table replicates the first four columns separately for single mother families (Columns 5 to 8) and families in which both biological parents are present (Columns 9 to 12). The differential returns by gender documented in the first four columns are broadly similar across family types. If anything, they are somewhat larger among children raised by single mothers, especially for teenage motherhood, although for a number of the other parental input measures, the estimates are often noisier (likely in part reflecting the smaller sample sizes in this subgroup of the data).

Appendix Table A9 presents the results of the Oaxaca-decompositions associated with the estimation of these regressions. Model 1 considers columns 5, 6, 9 and 10 in Tables 12A and 12B and according to this, it appears that boys' higher returns to the HOME index, parental warmth index and discipline can explain up to 13 percent of the larger gender gap in externalizing behavior in fifth grade in broken families, and 15 percent of the larger gender gap in eighth grade suspension. Model 2, corresponding to columns 7, 8, 11 and 12, includes family SES and teenage motherhood and together, these additional factors explain up to 60 (51) percent of the larger gender gap in externalizing behavior (grade suspension) among broken families.

In Table 13, we present the results of a final model (Model 3) where we replicate the analysis from Model 2 but include one additional control: the child's level of externalizing problems as measured in the fall of kindergarten. In other words, we now hold children's behavior in kindergarten constant and estimate the returns to kindergarten parental inputs on future noncognitive outcomes. This specification addresses the possibility that differences in the levels and 
returns to parental inputs could be merely picking up gender differences in initial externalizing behavior. For example, mothers could be spending less time and be less warm toward their boys because boys are more ill behaved than girls, especially in single-parent families. Another possibility is that gender differences in returns could arise because non-cognitive problems are more persistent among boys than among girls. By controlling for the child's initial behavior (in Fall-K), this gets us closer to being able to interpret our estimated coefficients in Table 13 as evidence of gender differences in the returns to parental inputs. The results in Table 13 and the Oaxaca decompositions in Model 3 in Appendix Table A7 indicate that controlling for the child's behavior in the fall of kindergarten leaves our main findings virtually unchanged. We continue to observe larger returns to higher levels of parental inputs and parental quality for boys compared to girls.

Finally, one potential reverse causation story for the differential returns we observe is that parents may systematically adjust their input in response to the behavior of their boys and girls for example, one possibility is that parents spend more time with boys who are well behaved but do not discriminate when it comes to spending time with girls. Appendix Table A10 sheds some light on this issue by estimating dynamic specifications that relate future parental inputs (in Grade 3 and Grade 5) on past behavior (externalizing behavior in the fall of kindergarten). ${ }^{24} \mathrm{We}$ estimate these regressions separately for boys and girls in single mother and intact families. Panel A reports results from regressions of the HOME Index in Kindergarten (columns 1 to 4), Grade 3 (columns 5 to 8) and Grade 5 (columns 9 to 12) on measures of the child's externalizing behavior in the fall of kindergarten. When considering future parental inputs (columns 5 to 12), we additionally control for parents' parental inputs in the previous time period (fall of kindergarten). We find little evidence that parental inputs as measured by the HOME Index is affected significantly by a child's externalizing behavior in kindergarten; this is true for both boys and girls and across family types. Panels B is similar to Panel A with the outcome variable replaced by the parental warmth index in kindergarten (columns 1 to 4) and Grade 3 (columns 5 to 8). The warmth index was not measured in Grade 5. Unlike the HOME Index, it appears that parental warmth in Kindergarten and Grade 3 is negatively affected by the child's past behavior.

\footnotetext{
${ }^{24}$ We have also estimated fully dynamic specification where we look at the cumulative returns of the entire stream of past behavior (up till t-1), controlling for previous parental inputs (up till t-1). The results are broadly similar and are available upon request.
} 
The patterns in Panel B, however, run counter to the idea that parents respond more negatively to boys' misbehavior. For intact families, parental warmth in grade 3 is similarly negatively affected by past behavior for both girls and boys, while for single mom families, an opposite pattern emerges - single moms appear to be more likely to be less warm to their girls who misbehave, but appear unaffected by boys' past behavior. Finally Panel $\mathrm{C}$ replicates the analysis looking at whether the child was spanked last week as the outcome. Once again, we find little systematic evidence that the effect of past behavior on spanking is larger for boys than for girls. Furthermore, we do not find evidence in any of the dynamic regressions in Appendix Table A10 that parental inputs is particularly affected by past behavior among boys of single mom families relative to boys of intact families. These findings suggest that the differential returns documented cannot be fully explained by reverse causation.

\section{Conclusion}

While a study of the gender gap in non-cognitive skills is of intellectual interest per se, our primary motivation for undertaking this study is the accumulating evidence suggesting that boys' non-cognitive deficit might be a primary factor holding them back from completing the higher levels of education that are demanded in the skill-biased economies that now characterize most developed countries. We suggest that boys' higher tendency to act out, and develop conduct problems, might be particularly relevant to their relative absence in colleges.

The biological and medical literatures have rather convincingly established nature-based explanations for boys' non-cognitive deficit. The fact that we fail to isolate any subsample of the data where there is no gender gap in non-cognitive skills certainly reinforces our belief that biological forces are at play. However, our findings suggest that social, or nurture-based, influences are also important. In particular, we find that boys' higher likelihood to act out and eventually experience a school suspension is about twice as large in the sample of children raised by single mothers, as well as in the sample of children raised by teenage mothers. On the other hand, we fail to find any large or systematic variation in the gender gap in non-cognitive skills across some key features of the early school environment such as age of entry in kindergarten, how regimented or intellectually demanding the school environment is, teacher gender, or peers' non-cognitive skills. 
When we look deeper into the reasons as to why boys are doing especially poorly when raised by single mothers, we find evidence suggesting that a small but non-trivial part of their disadvantage might be related to differential inputs, with single mothers investing more in their girls and feeling emotionally closer to them. Nevertheless, these findings are imprecise due in part to the small sample sizes and imperfect input measures available in this dataset. Turning to another dataset, the American Time Use Survey, we find corroborating evidence suggesting that single mothers spend significantly more time on childcare related activities with their girls relative to their boys. In contrast, there is no gender difference in childcare among children residing in two-parent families. These patterns are observed among children below the age of three, suggesting that these differences in parental inputs arise early in a child's life.

Most striking though are our findings regarding gender differences in the non-cognitive returns to parental inputs. Across all family structures, we observe that boys' likelihood to act out is sharply reduced when faced with larger and better parental inputs. For girls, the relationship between parental inputs and behavioral outcomes appear to be much weaker. As these parental inputs are typically higher and of better quality in intact families, this largely contributes to why boys with single mothers are so much more disruptive and eventually face school suspension.

From a broader perspective, our findings are particularly relevant in light of a recent literature documenting a growing socio-economic gradient in the amount of time parents spend with children, with highly educated parents spending increasing amounts of time in childcare related activities (Guryan et al, 2008). If one takes our findings at face value, higher amounts of parental time might be extremely beneficial to the non-cognitive development of boys. Assuming that a certain share of boys are born at the risk of developing behavioral problems, higher levels of parental investment may prevent more of these at-risk boys from developing conduct problems. The fact that the growth in parental time is concentrated among more educated or higher SES families suggests we might see a growing socio-economic gradient in the gender gap in noncognitive skills and, consequently, college completion and future outcomes. 


\section{References}

Baron-Cohen, Simon. 2003. The Essential Difference. Men, Women, and the Extreme Male Brain. London: Allan Lane.

Beaman, R., Wheldal, K. and Kemp, C. 2006. "Differential teacher attention to boys and girls in the classroom." Educational Review. 58(3): 339-366.

Becker, Gary S., Hubbard, William H.J. and Murphy, Kevin M. 2010. "The Market for College Graduates and the Worldwide Boom in Higher Education of Women." American Economic Review. 100(2): 229-33.

Dahl, Gordon B. and Enrico Moretti. 2008. "The Demand for Sons." Review of Economic Studies. 75(4): 1085-1120.

Dee, Thomas S. 2006. "The Why Chromosome: How a Teacher's Gender Affects Boys and Girls.” Education Next. 6(4): 68-75.

Demaray, Michelle, Stacey Ruffalo, John Carlson, R. T. Busse, Amy Olson, Susan McManus and Amy Levanthal. "Social Skills Assessment: A Comparative Evaluation of Six Published Rating Scales." School Psychology Review 24: 648-671.

Duckworth, A.L., \& Seligman, M.E.P. (2005). Self-discipline outdoes IQ in predicting academic performance of adolescents. Psychological Science. 16, pp. 939-944.

Elder, Todd and Lubotsky, Darren. 2009. "Kindergarten Entrance Age and Children's Achievement: Impacts of State Policies, Family Background, and Peers." Journal of Human Resources. 44(3): 641-683.

Elliott, Stephen, Frank Gresham, Terry Freeman, and George McCloskey. 1988. "Teacher and Observed Rating of Children's Social Skills: Validation of the Social Skills Rating Scales." Journal of Psychoeducation Assessment. 6: 152-161.

Else-Quest, N.M., Shilbey Hyde, J., Hill Goldsmith, H., Van Hulle, C.A. 2006. “Gender Differences in Temperament: A Meta-Analysis.” Psychological Bulletin. 132(1): 33-72.

Entwisle, D. R., Alexander, K. L., \& Olson, L. S.2007. "Early schooling: The handicap of being poor and male.” Sociology of Education. 80:114-138.

Flossman, Anton L., Remi Piatek and Laura Wichert. 2006. "Going Beyond Returns to Education: The Role of Noncognitive Skills on Wages in Germany." Working Paper, University of Konstanz, ZEW.

Fortin, Nicole M., Philip Oreopoulos and Shelley Phipps. 2011. "Leaving Boys Behind: Gender Disparities in High Academic Achievement." Working Paper, Department of Economics, UBC. 
Fryer, Roland G. and Steven D. Levitt. 2010. "An Empirical Analysis of the Gender Gap in Mathematics.” American Economic Journal: Applied Economics, 2(2): 210-40.

Geary DC. 1998. "Male, Female: The Evolution of Human Sex Differences.” Washington, DC: American Psychological Association.

Geary DC. 2002. "Sexual selection and human life history. In Advances in Child Development and Behavior." ed. RV Kail, 30:41-100. San Diego, CA: Academic.

Gilliam, W. S. 2005. "Prekindergartners left behind: Expulsion rates in state prekindergarten programs.” Policy Brief Series No. 3, New Haven, CT: Yale University Foundation for Child Development.

Goldin, Claudia, Katz, Lawrence F. and Kuziemko, Ilyana. 2006. "The Homecoming of American College Women: The Reversal of the College Gender Gap." Journal of Economic Perspectives. 20(4): 133-156.

Guryan, Jonathan, Erik Hurst and Melissa S. Kearney. 2008. "Parental Education and Parental Time with Children." Journal of Economic Perspectives. 22(3): 23-46.

Heckman, James J., Malofeeva, Lena, Pinto, Rodrigo R. and Savelyev, Peter. 2009. 'Understanding the Mechanisms Through Which an Influential Early Childhood Program Boosted Adult Outcomes.', Working Paper, University of Chicago.

Heckman, James J., Rubinstein, Yona. 2001. "The Importance of Noncognitive skills: Lessons from the GED testing program.” American Economic Review. 91(2): 145-149.

Heckman, James J., Stixrud, Jora and Urzua, Sergio. 2006. "The Effects of Cognitive and NonCognitive Abilities on Labor Market Outcomes and Social Behavior." Journal of Labor Economics. 24(3): 411-482.

Jacob, Brian A. 2002. "Where the Boys Aren't: Non-cognitive Skills, Returns to School and the Gender Gap in Higher Education.” Economics of Education Review. 21(6):589-98.

Keenan K, Shaw D. 1997. “Developmental and social influences on young girls' early problem behavior.” Psychol. Bull. 121:95-113.

Kenney-Benson, G.A., Pomerantz, E.M., Ryan, A.M., Patrick, H. (2006) "Sex Differences in Math Performance: The Role of Children's Approach to Schoolwork." Developmental Psychology. Vol. 42, No.1, 11-26.

Knickmeyer R, Baron-Cohen AR, Raggatt P, Taylor K. 2005a. "Fetal testosterone, social relationships, and restricted interests in children.” J. Child Psychol. Psychiatry 462:198-210.

Knickmeyer R, Baron-Cohen S, Raggatt P, Taylor K, Hackett G. 2005b. "Fetal testosterone 
and empathy." Horm. Behav. 49:282-92.

Lundberg, Shelly, Pabilonia, Sabrina Wulff and Ward-Batts, Jennifer. 2007. "Time Allocation of Parents and Investments in Sons and Daughters." Working Paper, University of Washington.

Maccoby EE. 1998. "The Two Sexes: Growing Up Apart, Coming Together.” Cambridge, MA: Harvard Univ. Press.

McClure EB. 2000. "A meta-analytic review of sex differences in facial expression processing and their development in infants, children and adolescents." Psychol. Bull. 126:424-53.

Neidell, Matthew and Waldfogel, Jane. 2010. "Cognitive and Non-Cognitive Peer Effects in Early Education.” Review of Economics and Statistics. 92(3): 562-576.

Ready, D. D., LoGerfo, L. F., Burkam, D. T., \& Lee, V. E. (2005). Explaining girls' advantage in kindergarten literacy learning: Do classroom behaviors make a difference? Elementary School Journal. 106: 21-38.

Sax, Leonard. 2007. Boys Adrift: The Five Factors Driving the Growing Epidemic of Unmotivated Boys and Underachieving Young Men. New York: Basic Books.

Segal, Carmit. 2008. “Classroom Behavior.” Journal of Human Resources. 43(4): 783-814.

Segal, Carmit. 2011. "Misbehavior, Education and Labor Market Outcomes." The Journal of the European Economic Association, Forthcoming.

Silverman, Irwin W. 2003. "Gender Differences in Delay of Gratification: A Meta-Analysis." Sex Roles. 49 (9-10): 451-63.

Szatmari, Peter, Offord, David R., Boyle, Michael H. 1989. "Ontario Child Health Study: Prevalence of attention deficit disorder with hyperactivity." Journal of Child Psychology and Psychiatry. 30(2): 219-230.

Zahn-Waxler, Caroline, Elizabeth A. Shirtcliff, Kristine Marceau. 2008. "Disorders of Childhood and Adolescence: Gender and Psychopathology." Annual Review of Clinical Psychology. 4:275303. 


\section{Figure 1: Teacher Reported Externalizing Behavior from Fall-K to Grade 5 by Gender and Family Structure, SES and Age at First Birth}

Teacher Reported Externalizing Behavior
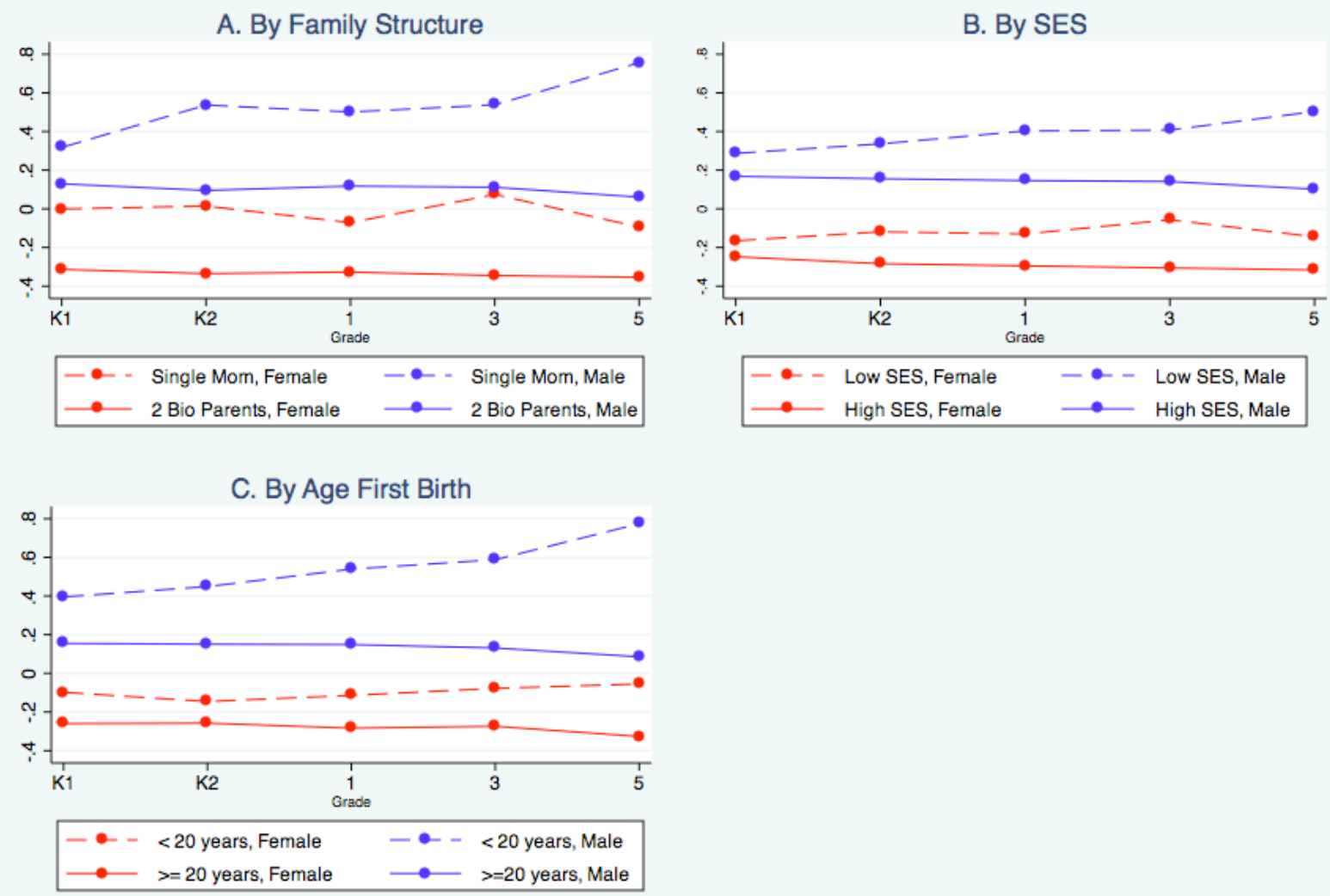

Notes: The basic sample restrictions are described in the text. In addition, for each grade, the sample is further restricted to children with non-missing teacher reported externalizing behavior ratings in that year. The teacherreported externalizing behavior index is standardized with mean 0 and standard deviation 1 in the full, weighted sample in each grade. Panel A plots the standardized teacher ratings in each grade separately by gender (red for girls and blue for boys) and family structure (dashed lines indicate single mom families and sold lines indicate intact families where both biological parents are present). Panel B plots the teacher ratings separately by gender and family SES (dashed lines indicate families in the lowest two quintiles of SES while the solid lines indicate families in the highest three quintiles). Panel $\mathrm{C}$ plots the teacher ratings by gender and mother's age at first birth (dashed lines indicate children with mothers who were aged less than 20 years at first birth while the solid lines indicate children whose mother's were 20 years or older at first birth). Observations are weighted by eighth grade parent panel weights $\left(\mathrm{C} 1 \_7 \mathrm{FP} 0\right)$. 
Table 1: Relationship between suspension and future educational outcomes in NELS:1988 and NLSY:1997

Panel A: NELS 1988

Within 12 years of 8th Grade (in 2000)

HS Graduate Attend College College Graduate

Suspended in the first half of the

quarter/semester (Grade 10)

Reading Scores (Grade 10)

$-0.167 * * *$
$[0.018]$

$-0.006$

[0.008]

Math Scores (Grade 10)

$0.076 * * *$

[0.008]

9,858

Observations

0.135

R-squared

$-0.155 * * *$
$[0.021]$
$0.064 * * *$
$[0.012]$
$0.188 * * *$
$[0.011]$
9,803
0.274

$-0.092 * * *$

[0.016]

$0.047 * * *$

[0.009]

$0.184 * * *$

[0.009]

9,770

0.251

Panel B: NLSY 1997

HS Graduate Attend College College Graduate

Within 10 years of base year (in 2007):

Ever Suspended from School in

1997

$\begin{array}{cc}-0.206 * * * & -0.190 * * * \\ {[0.017]} & {[0.018]} \\ 0.108 * * * & 0.241 * * * \\ {[0.006]} & {[0.007]} \\ \text { yes } & \text { yes } \\ 4,714 & 4,689 \\ 0.179 & 0.302\end{array}$

$-0.152 * * *$

[0.013]

ASVAB Score

$241 * * *$

$0.201 * * *$

Observations

4,714

R-squared

0.302

[0.006]

yes

4,714

0.272

Notes: Panel A (NELS 1988) - The sample includes students who were 8th graders in 1988. "HS Graduate" is a dummy variable indicating whether the student received a high school diploma (excl. GED), "Attend College" indicates that the highest grade attended includes 1 or more years of college. "College Graduate" is a dummy variable that indicates that the student received a Bachelor's degree. The sample sizes are not identical in each of the columns due to non-response on the question required to infer their education status. Coefficients are similar if we restrict the sample to individuals who responded to all three questions. Additional covariates include a female dummy, race dummies and dummies for year of birth. Observations are weighted using panel weights in the 4th follow-up survey (2000). Robust standard errors in parentheses.

Panel B (NLSY 1997) - The sample includes children who were born in 1980-1984 (Grade 7 to Grade 11 in 1997). The dependent variables are measured within 10 years of the base year, in 2007. "HS Graduate" is a dummy variable indicating whether the student received a high school diploma (excl. GED), "Attend College" indicates that the highest grade attended includes 1 or more years of college. "College Graduate" is a dummy variable that indicates that the student received a Bachelor's degree. Additional covariates include year of birth dummies and a female dummy. The sample sizes are not identical in each of the columns due to non-response on the question required to infer whether the individual attended college (HS Graduate and College Graduate were inferred from the same question). Coefficients are similar if we restrict the sample to individuals who responded to both questions. Observations are weighted using Round 11 (2007) weights provided in the NLSY. Robust standard errors in parentheses.

$* * *$ significant at $1 \% * * 5 \% * 10 \%$. 
Table 2: Teacher Ratings of Non-cognitive Skills, Suspension, Retention and Test Scores

\begin{tabular}{|c|c|c|c|}
\hline & Girls & Boys & $\begin{array}{c}\text { Difference (Girls- } \\
\text { Boys) }\end{array}$ \\
\hline \multicolumn{4}{|l|}{ Externalizing Behaviors: } \\
\hline Fall Kindergarten & $\begin{array}{c}-0.222 \\
(0.841)\end{array}$ & $\begin{array}{c}0.213 \\
(1.090)\end{array}$ & $\begin{array}{c}-0.435 * * * \\
{[0.044]}\end{array}$ \\
\hline Spring Kindergarten & $\begin{array}{l}-0.232 \\
(0.874)\end{array}$ & $\begin{array}{c}0.222 \\
(1.061)\end{array}$ & $\begin{array}{c}-0.454 * * * \\
{[0.045]}\end{array}$ \\
\hline Grade 1 & $\begin{array}{l}-0.244 \\
(0.846)\end{array}$ & $\begin{array}{c}0.240 \\
(1.079)\end{array}$ & $\begin{array}{c}-0.484 * * * \\
{[0.044]}\end{array}$ \\
\hline Grade 3 & $\begin{array}{l}-0.232 \\
(0.866)\end{array}$ & $\begin{array}{c}0.231 \\
(1.069)\end{array}$ & $\begin{array}{c}-0.463 * * * \\
{[0.049]}\end{array}$ \\
\hline Grade 5 & $\begin{array}{l}-0.263 \\
(0.826)\end{array}$ & $\begin{array}{c}0.252 \\
(1.084)\end{array}$ & $\begin{array}{c}-0.515 * * * \\
{[0.046]}\end{array}$ \\
\hline \multicolumn{4}{|l|}{ Self Control: } \\
\hline Fall Kindergarten & $\begin{array}{c}0.183 \\
(0.940)\end{array}$ & $\begin{array}{c}-0.177 \\
(1.024)\end{array}$ & $\begin{array}{c}0.360 * * * \\
{[0.044]}\end{array}$ \\
\hline Spring Kindergarten & $\begin{array}{c}0.196 \\
(0.923)\end{array}$ & $\begin{array}{l}-0.187 \\
(1.034)\end{array}$ & $\begin{array}{c}0.383 * * * \\
{[0.045]}\end{array}$ \\
\hline Grade 1 & $\begin{array}{c}0.200 \\
(0.919)\end{array}$ & $\begin{array}{l}-0.197 \\
(1.037)\end{array}$ & $\begin{array}{c}0.397 * * * \\
{[0.045]}\end{array}$ \\
\hline Grade 3 & $\begin{array}{l}0.183 \\
(0.915)\end{array}$ & $\begin{array}{l}-0.183 \\
(1.047)\end{array}$ & $\begin{array}{c}0.366 * * * \\
{[0.048]}\end{array}$ \\
\hline Grade 5 & $\begin{array}{c}0.231 \\
(0.903)\end{array}$ & $\begin{array}{c}-0.221 \\
(1.038)\end{array}$ & $\begin{array}{c}0.452 * * * \\
{[0.045]}\end{array}$ \\
\hline \multicolumn{4}{|l|}{ Approaches to Learning: } \\
\hline Fall Kindergarten & $\begin{array}{c}0.233 \\
(0.929)\end{array}$ & $\begin{array}{l}-0.223 \\
(1.015)\end{array}$ & $\begin{array}{c}0.456 * * * \\
{[0.043]}\end{array}$ \\
\hline Spring Kindergarten & $\begin{array}{c}0.253 \\
(0.898)\end{array}$ & $\begin{array}{l}-0.241 \\
(1.032)\end{array}$ & $\begin{array}{c}0.494 * * * \\
{[0.043]}\end{array}$ \\
\hline Grade 1 & $\begin{array}{c}0.221 \\
(0.938)\end{array}$ & $\begin{array}{l}-0.217 \\
(1.011)\end{array}$ & $\begin{array}{c}0.438 * * * \\
{[0.045]}\end{array}$ \\
\hline Grade 3 & $\begin{array}{c}0.264 \\
(0.908)\end{array}$ & $\begin{array}{l}-0.264 \\
(1.018)\end{array}$ & $\begin{array}{c}0.528 * * * \\
{[0.045]}\end{array}$ \\
\hline Grade 5 & $\begin{array}{c}0.319 \\
(0.881)\end{array}$ & $\begin{array}{l}-0.306 \\
(1.011)\end{array}$ & $\begin{array}{c}0.625 * * * \\
{[0.042]}\end{array}$ \\
\hline \multicolumn{4}{|l|}{ Interpersonal Skills: } \\
\hline Fall Kindergarten & $\begin{array}{c}0.194 \\
(0.961)\end{array}$ & $\begin{array}{l}-0.187 \\
(1.002)\end{array}$ & $\begin{array}{c}0.381 * * * \\
{[0.043]}\end{array}$ \\
\hline Spring Kindergarten & $\begin{array}{c}0.202 \\
(0.958)\end{array}$ & $\begin{array}{l}-0.194 \\
(1.002)\end{array}$ & $\begin{array}{c}0.396 * * * \\
{[0.044]}\end{array}$ \\
\hline Grade 1 & $\begin{array}{c}0.218 \\
(0.945)\end{array}$ & $\begin{array}{l}-0.215 \\
(1.006)\end{array}$ & $\begin{array}{c}0.433 * * * \\
{[0.045]}\end{array}$ \\
\hline Grade 3 & $\begin{array}{c}0.232 \\
(0.933)\end{array}$ & $\begin{array}{l}-0.233 \\
(1.011)\end{array}$ & $\begin{array}{c}0.465 * * * \\
{[0.046]}\end{array}$ \\
\hline Grade 5 & $\begin{array}{c}0.284 \\
(0.894)\end{array}$ & $\begin{array}{l}-0.276 \\
(1.020)\end{array}$ & $\begin{array}{c}0.560 * * * \\
{[0.044]}\end{array}$ \\
\hline \multicolumn{4}{|l|}{ Internalizing Problems: } \\
\hline Fall Kindergarten & $\begin{array}{l}-0.036 \\
(0.998)\end{array}$ & $\begin{array}{c}0.035 \\
(1.001)\end{array}$ & $\begin{array}{l}-0.071^{*} \\
{[0.042]}\end{array}$ \\
\hline Spring Kindergarten & $\begin{array}{l}-0.041 \\
(0.995)\end{array}$ & $\begin{array}{c}0.039 \\
(1.003)\end{array}$ & $\begin{array}{l}-0.080^{*} \\
{[0.045]}\end{array}$ \\
\hline Grade 1 & -0.048 & 0.047 & $-0.096 * *$ \\
\hline
\end{tabular}




$\begin{array}{cccc} & (0.947) & (1.048) & {[0.044]} \\ \text { Grade } 3 & -0.085 & 0.084 & -0.169 * * * \\ & (0.909) & (1.076) & {[0.046]} \\ \text { Grade } 5 & -0.089 & 0.086 & -0.175 * * * \\ & (0.904) & (1.078) & {[0.044]}\end{array}$

Ever been retained from

Fall-K to Grade $8 \quad 0.080$

$(0.271)$

0.156

$-0.076^{* * *}$

In/Out of School

$(0.363)$

[0.016]

Suspension in Grade 8

0.083

$(0.276)$

0.237

$(0.425)$

$-0.154 * * *$

Reading Scores:

Fall Kindergarten $\quad 0.095$

(1.019)

$-0.092$

[0.017]

Spring Kindergarten

0.107

$(0.972)$

$0.188 * * *$

$-0.103$

[0.042]

(0.985)

Grade 1

0.137

$(0.943)$

(1.003)

$0.209 * * *$

$-0.131$

[0.044]

Grade 3

0.118

(1.035)

$-0.117$

$0.268 * * *$

(0.943)

Grade 5

0.104

(1.041)

[0.044]

$0.235 * * *$

$-0.101$

[0.043]

(0.927)

Grade 8

0.112

(0.943)

(1.056)

$0.205 * * *$

$-0.112$

[0.044]

(1.042)

$0.224 * * *$

[0.044]

Math Scores:

Fall Kindergarten

0.006

$-0.006$

0.012

(0.966)

Spring Kindergarten

$-0.012$

(0.962)

Grade 1

0.002

(0.953)

Grade 3

$-0.092$

(1.032)

[0.041]

0.012

$-0.024$

(1.035)

[0.042]

$-0.002$

0.005

(1.043)

[0.043]

0.090

-0.181 ***

(0.971)

Grade 5

$-0.073$

(0.988)

Grade 8

$-0.026$

(0.969)

(1.020)

[0.044]

0.070

(1.007)

$-0.144 * * *$

[0.044]

0.025

$-0.051$

(1.029)

[0.045]

Notes: Summary statistics are based on the restricted sample of children with non-missing observations for each outcome. Teacher ratings and test scores are standardized to have a mean of zero and standard deviation one in the weighted sample after imposing the sample restrictions. Please refer to the text for sample restrictions. Observations are weighted using eighth grade parent panel weights (C1_7FP0). Robust standard errors are reported for differences in the means across genders ***significant at $1 \% * * 5 \% * 10 \%$. 
Table 3: Trends over Time in the Gender Gap in School Suspension

\begin{tabular}{|c|c|c|c|c|c|}
\hline \multicolumn{6}{|c|}{ Ever Suspended by the time child was in: } \\
\hline \multicolumn{3}{|c|}{ HSB (1980), 10th Grade } & \multicolumn{3}{|c|}{ NELS (1990), 10th Grade } \\
\hline Female & Male & Diff (Female-Male) & Female & Male & Diff (Female-Male) \\
\hline 0.086 & 0.157 & $\begin{array}{c}-0.071 * * * \\
{[0.005]} \\
\end{array}$ & 0.115 & 0.188 & $\begin{array}{c}-0.074 * * * \\
{[0.008]} \\
\end{array}$ \\
\hline \multicolumn{3}{|c|}{ ELS (2002), 10th Grade } & \multicolumn{3}{|c|}{ ECLS (2006), 8th Grade } \\
\hline Female & Male & Diff (Female-Male) & Female & Male & Diff (Female-Male) \\
\hline 0.127 & 0.207 & $\begin{array}{c}-0.079 * * * \\
{[0.007]}\end{array}$ & 0.110 & 0.244 & $\begin{array}{c}-0.133^{* * * *} \\
{[0.008]}\end{array}$ \\
\hline
\end{tabular}

Sources: High School and Beyond (HSB) 1980 Sophomore Cohort; National Educational Longitudinal Survey (NELS) 1988; Educational Longitudinal Survey (ELS) 2002; Early Childhood Longitudinal Survey (ECLS) Kindergarten Cohort 1998/1999.

Notes: (1) HSB and ELS data are based on a nationally representative sample of 10th Graders in the base year. NELS is based on a sample of 8th graders in the base year. ECLS is based on a sample of kindergarteners. For comparability with the HSB and ELS data, we restrict the NELS sample to include only students who are in 10th Grade in the first-follow up. The ECLS sample consists of all respondents who were Kindergarteners in 1998/1999 regardless of their actual grade in 2006. The sample includes all races. All estimates are weighted by the appropriate cross-sectional weights available in the datasets. $* * *$ significant at $1 \% * * 5 \% * 10 \%$. 
Table 4: Relationship between Suspension and Test Scores in Grade 8 on Non-Cognitive and Cognitive Skills

\begin{tabular}{|c|c|c|c|c|c|c|}
\hline & \multicolumn{2}{|c|}{ Suspension in Grade 8} & \multicolumn{2}{|c|}{ Reading Scores } & \multicolumn{2}{|c|}{ Math Scores } \\
\hline & \multicolumn{6}{|c|}{ Teacher reported non-cognitive skills measured in: } \\
\hline & Grade 5 & Fall-K & Grade 5 & Fall-K & Grade 5 & Fall-K \\
\hline \multirow[t]{2}{*}{ Externalizing Behavior } & $0.089 * * *$ & $0.050 * * *$ & -0.017 & -0.048 & -0.018 & 0.003 \\
\hline & {$[0.013]$} & {$[0.014]$} & {$[0.031]$} & {$[0.031]$} & [0.030] & {$[0.031]$} \\
\hline \multirow[t]{2}{*}{ Self-Control } & -0.017 & $-0.028 *$ & $-0.085^{* *}$ & -0.058 & -0.054 & -0.026 \\
\hline & {$[0.017]$} & {$[0.015]$} & {$[0.043]$} & {$[0.039]$} & {$[0.043]$} & {$[0.041]$} \\
\hline \multirow[t]{2}{*}{ Approaches to Learning } & 0.012 & -0.002 & $0.341 * * *$ & $0.276 * * *$ & $0.350 * * *$ & $0.350 * * *$ \\
\hline & {$[0.013]$} & {$[0.014]$} & {$[0.030]$} & {$[0.028]$} & {$[0.031]$} & {$[0.031]$} \\
\hline \multirow[t]{2}{*}{ Interpersonal Skills } & $-0.035 * *$ & 0.016 & 0.045 & -0.023 & -0.006 & -0.060 \\
\hline & {$[0.014]$} & {$[0.015]$} & {$[0.037]$} & {$[0.034]$} & {$[0.040]$} & {$[0.037]$} \\
\hline \multirow[t]{2}{*}{ Internalizing Behavior } & 0.015 & -0.007 & $-0.074 * * *$ & $-0.048 * *$ & $-0.091 * * *$ & -0.034 \\
\hline & {$[0.011]$} & {$[0.009]$} & {$[0.024]$} & {$[0.023]$} & {$[0.025]$} & {$[0.022]$} \\
\hline \multirow[t]{2}{*}{ Reading } & -0.001 & -0.018 & & & & \\
\hline & {$[0.012]$} & {$[0.011]$} & & & & \\
\hline \multirow[t]{2}{*}{ Math } & -0.013 & $-0.027 * *$ & & & & \\
\hline & {$[0.012]$} & {$[0.012]$} & & & & \\
\hline Background Controls & yes & yes & yes & yes & yes & yes \\
\hline Observations & 5524 & 5112 & 5143 & 5399 & 5173 & 5524 \\
\hline R-squared & 0.21 & 0.13 & 0.23 & 0.27 & 0.25 & 0.19 \\
\hline
\end{tabular}

Notes: Each column is a separate regression of suspension and test scores in grade 8 on measures of non-cognitive and cognitive skills in grade 5 or fall-kindergarten. Background controls include a female dummy, race dummies (black, hisp, asian, other), age at assessment at Fall-K, age-squared, birthweight, number of older brothers, younger brothers, older sisters, younger sisters and dummies for region and urbanicity. Observations are weighted using grade 8 parent panel weights. Robust standard errors are reported. $* * *$ Significant at $1 \%$ level, $* * 5 \% * 10 \%$. 


\begin{tabular}{|c|c|c|c|c|}
\hline & Full Sample & Girls & Boys & $\begin{array}{c}\text { Difference } \\
\text { (Girls-Boys) }\end{array}$ \\
\hline \multirow[t]{2}{*}{ Biological mother only } & 0.186 & 0.184 & 0.187 & -0.003 \\
\hline & $(0.389)$ & $(0.388)$ & $(0.390)$ & {$[0.018]$} \\
\hline \multirow[t]{2}{*}{ Both biological parents } & 0.710 & 0.712 & 0.708 & 0.004 \\
\hline & $(0.454)$ & $(0.453)$ & $(0.455)$ & {$[0.021]$} \\
\hline \multirow[t]{2}{*}{ Other family structure } & 0.104 & 0.104 & 0.105 & -0.001 \\
\hline & $(0.306)$ & $(0.305)$ & $(0.307)$ & {$[0.015]$} \\
\hline \multirow[t]{2}{*}{ Mother $<20$ years at first birth } & 0.238 & 0.234 & 0.241 & -0.007 \\
\hline & $(0.426)$ & $(0.423)$ & $(0.428)$ & {$[0.020]$} \\
\hline \multirow[t]{2}{*}{ Family SES: First Quintile (Lowest) } & 0.154 & 0.138 & 0.169 & $-0.031 *$ \\
\hline & $(0.361)$ & $(0.345)$ & $(0.374)$ & {$[0.016]$} \\
\hline \multirow[t]{2}{*}{ 2nd Quintile } & 0.189 & 0.173 & 0.205 & $-0.032 *$ \\
\hline & $(0.392)$ & $(0.378)$ & $(0.404)$ & {$[0.018]$} \\
\hline \multirow[t]{2}{*}{ 3rd Quintile } & 0.194 & 0.204 & 0.186 & 0.018 \\
\hline & $(0.396)$ & $(0.403)$ & $(0.389)$ & {$[0.017]$} \\
\hline \multirow[t]{2}{*}{ 4th Quintile } & 0.229 & 0.240 & 0.218 & 0.021 \\
\hline & $(0.420)$ & $(0.427)$ & $(0.413)$ & {$[0.018]$} \\
\hline \multirow[t]{2}{*}{ 5th Quintile (highest) } & 0.234 & 0.246 & 0.222 & 0.024 \\
\hline & $(0.423)$ & $(0.431)$ & $(0.416)$ & {$[0.017]$} \\
\hline \multirow[t]{2}{*}{ Parental Input Composite (HOME Index) } & 0.000 & 0.087 & -0.084 & $0.170 * * *$ \\
\hline & $(1.000)$ & $(0.974)$ & $(1.018)$ & {$[0.042]$} \\
\hline \multirow[t]{2}{*}{ Indicator if HOME Index $>$ median } & 0.292 & 0.313 & 0.271 & $0.041 * *$ \\
\hline & $(0.455)$ & $(0.464)$ & $(0.445)$ & [0.019] \\
\hline \multicolumn{5}{|l|}{ Components of Parental Input Composite: } \\
\hline \multirow[t]{2}{*}{ Parent reads to child at least 3 times/week } & 0.826 & 0.851 & 0.802 & $0.050 * * *$ \\
\hline & $(0.379)$ & $(0.356)$ & $(0.399)$ & {$[0.017]$} \\
\hline \multirow[t]{2}{*}{ Number of books $(1:>=20$ books $)$} & 0.873 & 0.892 & 0.854 & $0.038 * *$ \\
\hline & $(0.333)$ & $(0.310)$ & $(0.353)$ & {$[0.015]$} \\
\hline \multirow[t]{2}{*}{ Took child to library in past month (1: Yes) } & 0.560 & 0.574 & 0.546 & 0.027 \\
\hline & $(0.496)$ & $(0.495)$ & $(0.498)$ & {$[0.021]$} \\
\hline \multirow[t]{2}{*}{ Took child to concert in past month (1: Yes) } & 0.396 & 0.428 & 0.366 & $0.062 * * *$ \\
\hline & $(0.489)$ & $(0.495)$ & $(0.482)$ & {$[0.021]$} \\
\hline \multirow[t]{2}{*}{ Took child to museum in past month (1: Yes) } & 0.317 & 0.323 & 0.311 & 0.012 \\
\hline & $(0.465)$ & $(0.468)$ & $(0.463)$ & {$[0.020]$} \\
\hline \multirow{3}{*}{$\begin{array}{l}\text { Child participates in at least one extra- } \\
\text { curricular activity }\end{array}$} & & & & \\
\hline & 0.671 & 0.694 & 0.649 & $0.045 * *$ \\
\hline & $(0.470)$ & $(0.461)$ & $(0.477)$ & {$[0.020]$} \\
\hline \multirow[t]{2}{*}{ Spanked child last week } & 0.279 & 0.264 & 0.293 & -0.029 \\
\hline & $(0.449)$ & $(0.441)$ & $(0.455)$ & {$[0.020]$} \\
\hline \multirow{3}{*}{$\begin{array}{l}\text { Emotional Supportiveness Composite } \\
\text { (WARMTH Index) }\end{array}$} & & & & \\
\hline & 0.000 & 0.054 & -0.051 & $0.105 * *$ \\
\hline & $(1.000)$ & $(0.958)$ & $(1.036)$ & {$[0.046]$} \\
\hline \multirow[t]{2}{*}{ Indicator if WARMTH Index>median } & 0.488 & 0.505 & 0.473 & 0.032 \\
\hline & $(0.500)$ & $(0.500)$ & $(0.499)$ & {$[0.022]$} \\
\hline
\end{tabular}

Components of Emotional Supportiveness Composite (scale of 0 to 3, 0: least warm response and 3: most warm response):

Warm, close time with child

$\begin{array}{cccc}2.704 & 2.720 & 2.690 & 0.030 \\ (0.554) & (0.531) & (0.575) & {[0.025]} \\ 2.793 & 2.814 & 2.773 & 0.041^{*} * \\ (0.464) & (0.441) & (0.484) & {[0.020]}\end{array}$

Child likes me 
Always show child love

Express affection

Too busy to play with child

Hard to be warm to child

Being parent harder than expected

Child does things to bother me

Sacrifice to meet child's needs

Feel trapped as parent

Often feel angry with child

Child harder to care for

Child is more work than pleasure

Average from Kindergarten to Grade 3:

Parental Input Composite

Emotional Supportiveness Composite

Spanked Child Last Week

Expect child to go to college (Kindergarten)

Expect child to go to college (Grade 1)

Expect child to go to college (Grade 3)

Expect child to go to college (Grade 5)

Expect child to go to college (Grade 8)

\begin{tabular}{|c|c|c|c|}
\hline 2.437 & 2.426 & 2.448 & -0.022 \\
\hline (0.707) & $(0.722)$ & $(0.691)$ & {$[0.032]$} \\
\hline 2.420 & 2.432 & 2.409 & 0.023 \\
\hline (0.760) & $(0.753)$ & $(0.766)$ & [0.032] \\
\hline 2.683 & 2.655 & 2.710 & $-0.055^{* *} *$ \\
\hline (0.652) & (0.689) & $(0.614)$ & [0.027] \\
\hline 2.896 & 2.904 & 2.888 & 0.016 \\
\hline (0.388) & $(0.362)$ & $(0.412)$ & {$[0.016]$} \\
\hline 1.398 & 1.428 & 1.370 & 0.058 \\
\hline (1.205) & (1.210) & (1.199) & {$[0.052]$} \\
\hline 2.283 & 2.325 & 2.243 & $0.082 * *$ \\
\hline (0.789) & $(0.765)$ & $(0.810)$ & {$[0.033]$} \\
\hline 2.111 & 2.141 & 2.083 & 0.058 \\
\hline (1.076) & (1.064) & (1.088) & {$[0.046]$} \\
\hline 2.753 & 2.774 & 2.734 & 0.041 \\
\hline (0.592) & $(0.548)$ & $(0.632)$ & {$[0.028]$} \\
\hline 2.724 & 2.749 & 2.701 & $0.047 * *$ \\
\hline (0.516) & $(0.510)$ & $(0.520)$ & [0.023] \\
\hline 2.789 & 2.840 & 2.740 & $0.100 * * *$ \\
\hline (0.596) & $(0.502)$ & $(0.670)$ & [0.029] \\
\hline 2.748 & 2.775 & 2.723 & $0.052 *$ \\
\hline (0.630) & $(0.568)$ & $(0.684)$ & {$[0.030]$} \\
\hline 0.000 & 0.112 & -0.107 & $0.219 * * *$ \\
\hline (1.000) & $(0.954)$ & (1.031) & [0.043] \\
\hline 0.000 & 0.082 & -0.078 & $0.159 * * *$ \\
\hline (1.000) & $(0.958)$ & (1.033) & [0.046] \\
\hline 0.221 & 0.204 & 0.237 & $-0.033 * *$ \\
\hline (0.313) & $(0.305)$ & $(0.319)$ & [0.014] \\
\hline 0.780 & 0.794 & 0.765 & 0.029 \\
\hline$(0.415)$ & $(0.404)$ & $(0.424)$ & [0.018] \\
\hline 0.754 & 0.783 & 0.727 & $0.056 * * *$ \\
\hline$(0.431)$ & $(0.412)$ & $(0.446)$ & [0.019] \\
\hline 0.790 & 0.823 & 0.757 & $0.066 * * *$ \\
\hline (0.408) & $(0.382)$ & $(0.429)$ & [0.018] \\
\hline 0.769 & 0.820 & 0.720 & $0.099 * * *$ \\
\hline$(0.422)$ & $(0.384)$ & $(0.449)$ & [0.018] \\
\hline 0.763 & 0.816 & 0.712 & $0.104 * * *$ \\
\hline$(0.426)$ & $(0.388)$ & $(0.453)$ & [0.019] \\
\hline
\end{tabular}

Notes: Summary statistics are based on the restricted sample of children with non-missing observations for each outcome. Please refer to the text for sample restrictions. Observations are weighted by eighth grade parent panel weights (C1_7FP0). Robust standard errors are reported for differences across gender ***significant at $1 \%$ level $* * 5 \% * 10 \%$. 


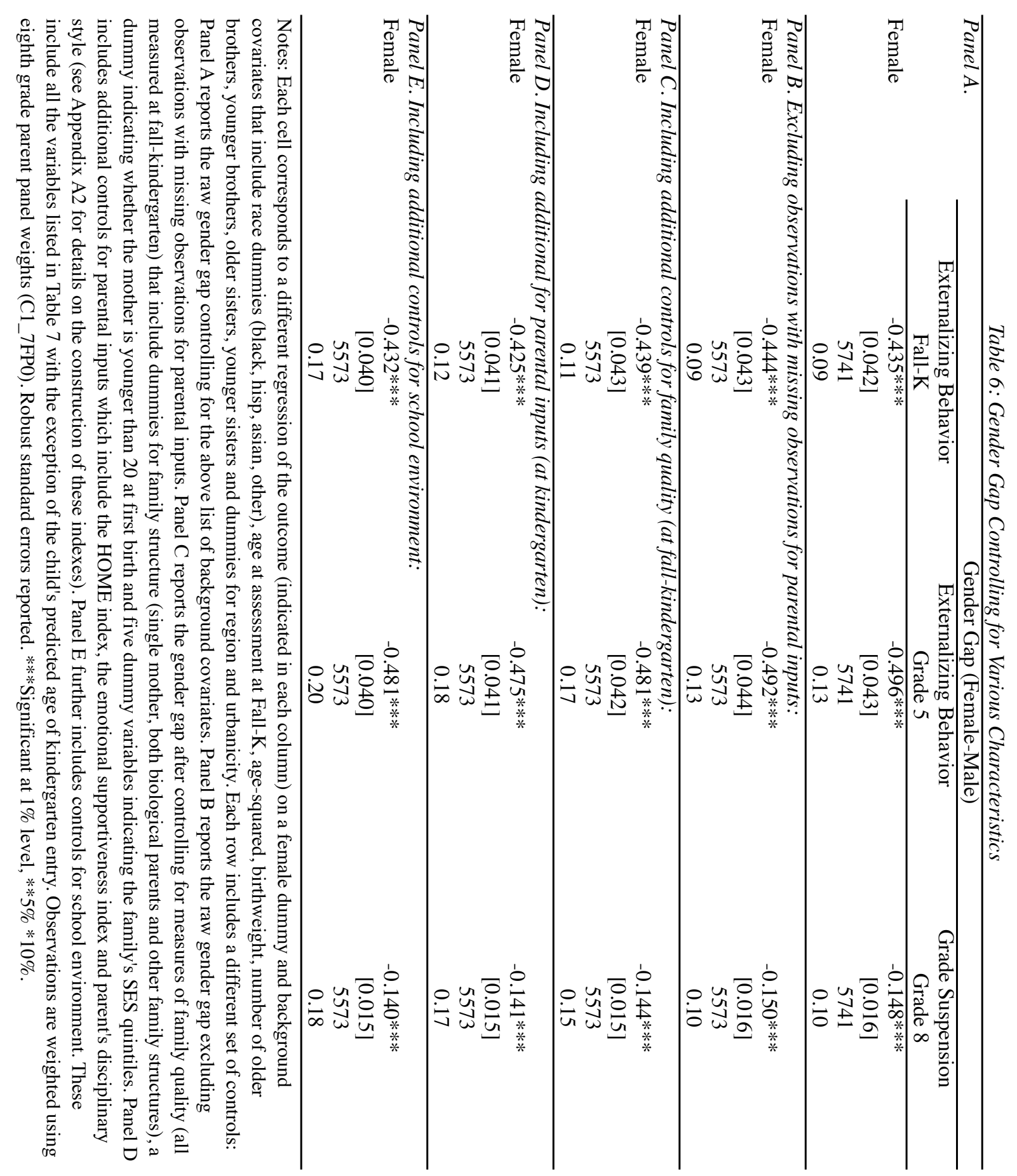




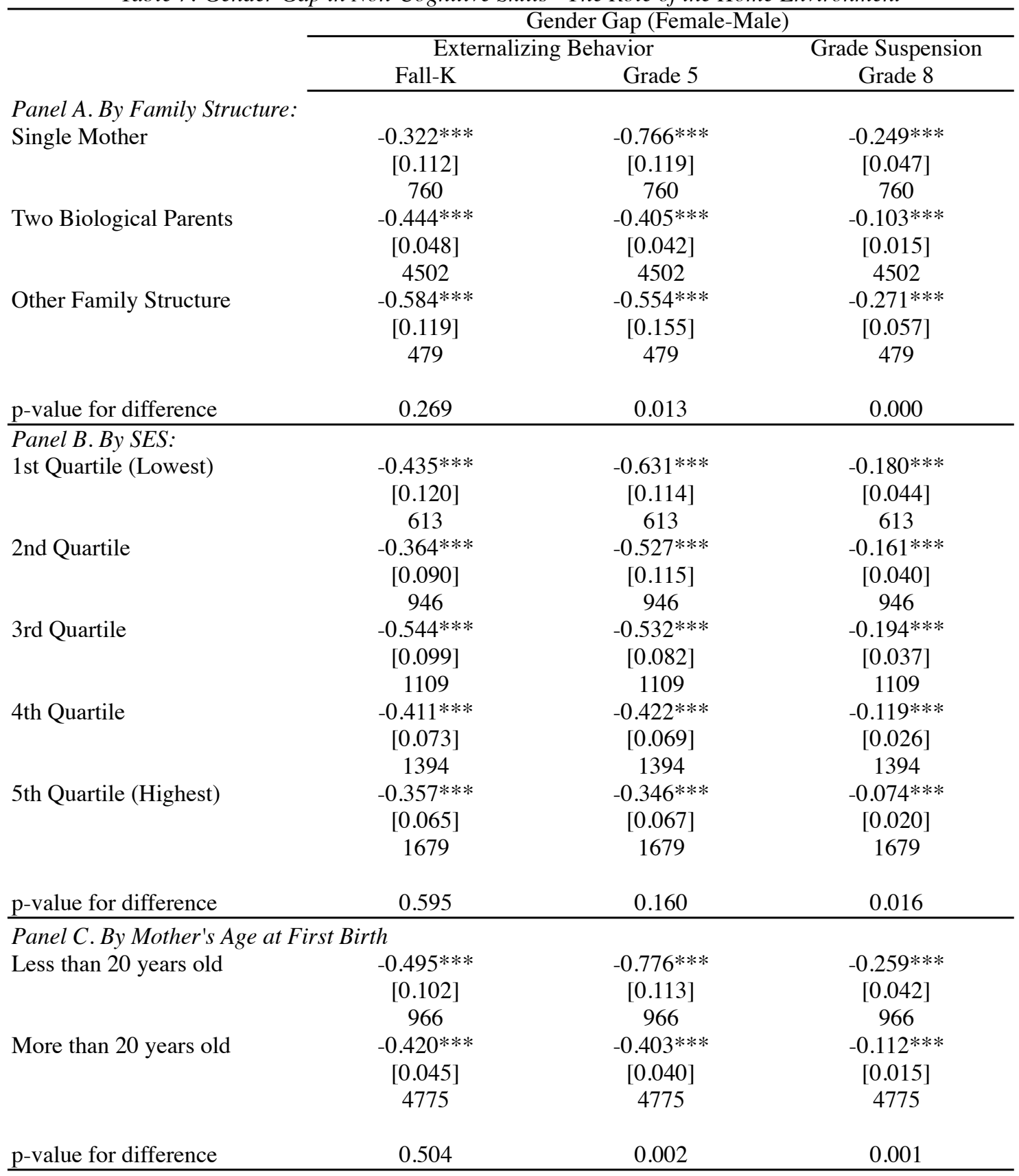

Notes: Each row corresponds to a different subset of the data. Each cell corresponds to a different regression of the outcome (indicated in each column) on a female dummy and background covariates that include race dummies (black, hisp, asian, other), age at assessment at Fall-K, age-squared, birthweight, number of older brothers, younger brothers, older sisters, younger sisters and dummies for region and urbanicity. The p-value for difference at the bottom of each panel tests whether the gender gaps for each subset of the data is statistically different. Sample is restricted to those with non-missing observations on family structure, mother's age at firstbirth, family SES, gender, the background covariates, fall-K and grade 5 teacher ratings of externalizing behavior and parental reports of school suspension in eighth grade. Observations are weighted using eighth grade parent panel weights. Robust standard errors reported. $* * *$ Significant at $1 \%$ level, $* * 5 \% * 10 \%$. 


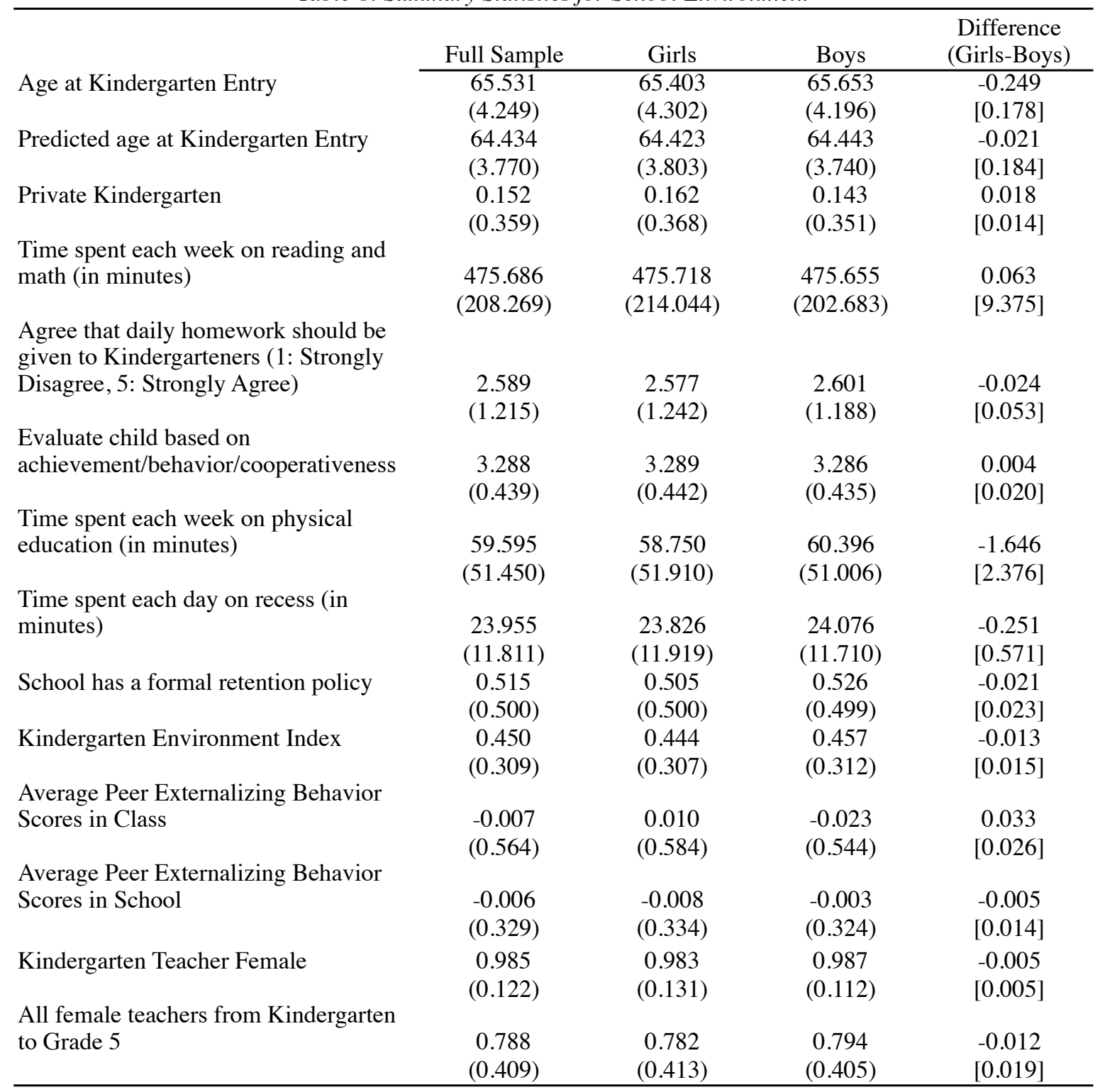

Notes: Summary statistics are based on the restricted sample of children with non-missing observations for each outcome. Please refer to the text for sample restrictions. Observations are weighted using eighth grade parent panel weights $\left(\mathrm{C} 1 \_7 \mathrm{FP} 0\right)$. Robust standard errors are reported for differences in the means across genders $* * *$ significant at $1 \% * * 5 \% * 10 \%$. 
Table 9: The Early School Environment

\begin{tabular}{|c|c|c|c|}
\hline & \multicolumn{3}{|c|}{ Gender Gap (Female-Male) } \\
\hline & \multicolumn{2}{|c|}{ Externalizing Behavior } & \multirow{2}{*}{$\begin{array}{c}\text { Grade Suspension } \\
\text { Grade } 8\end{array}$} \\
\hline & Fall-K & Grade 5 & \\
\hline \multicolumn{4}{|c|}{ A. Average Age at Kindergarten Entry: } \\
\hline \multirow[t]{3}{*}{ Above median } & $-0.491 * * *$ & $-0.503 * * *$ & $-0.133 * * *$ \\
\hline & {$[0.064]$} & {$[0.067]$} & {$[0.024]$} \\
\hline & 2465 & 2465 & 2465 \\
\hline \multirow[t]{3}{*}{ Below median } & $-0.390 * * *$ & $-0.488 * * *$ & $-0.155 * * *$ \\
\hline & {$[0.055]$} & {$[0.054]$} & {$[0.020]$} \\
\hline & 3275 & 3275 & 3275 \\
\hline pvalue of difference & 0.233 & 0.859 & 0.472 \\
\hline \multicolumn{4}{|c|}{ B. Average Predicted age at Kindergarten Entry: } \\
\hline \multirow[t]{3}{*}{ Above median } & $-0.448 * * *$ & $-0.559 * * *$ & $-0.164 * * *$ \\
\hline & [0.069] & {$[0.071]$} & {$[0.027]$} \\
\hline & 2079 & 2079 & 2079 \\
\hline \multirow[t]{3}{*}{ Below median } & $-0.451 * * *$ & $-0.455^{* * *}$ & $-0.137 * * *$ \\
\hline & {$[0.072]$} & {$[0.068]$} & {$[0.025]$} \\
\hline & 2270 & 2270 & 2270 \\
\hline pvalue of difference & 0.978 & 0.286 & 0.459 \\
\hline \multicolumn{4}{|l|}{ C. Kindergarten Type: } \\
\hline \multirow[t]{3}{*}{ Private } & $-0.326 * * *$ & $-0.279 * * *$ & $-0.088 * * *$ \\
\hline & {$[0.080]$} & {$[0.079]$} & {$[0.022]$} \\
\hline & 1355 & 1355 & 1355 \\
\hline \multirow[t]{3}{*}{ Public } & $-0.457 * * *$ & $-0.532 * * *$ & $-0.156^{* * *}$ \\
\hline & [0.047] & [0.047] & {$[0.018]$} \\
\hline & 4386 & 4386 & 4386 \\
\hline pvalue of difference & 0.157 & 0.006 & 0.017 \\
\hline \multicolumn{4}{|c|}{ D. Emphasis on Reading and Math: } \\
\hline \multirow[t]{3}{*}{ Above median } & $-0.478 * * *$ & $-0.477 * * *$ & $-0.136 * * *$ \\
\hline & {$[0.074]$} & {$[0.065]$} & {$[0.026]$} \\
\hline & 2263 & 2263 & 2263 \\
\hline \multirow[t]{3}{*}{ Below median } & $-0.401 * * *$ & $-0.508 * * *$ & $-0.152 * * *$ \\
\hline & {$[0.050]$} & {$[0.053]$} & {$[0.019]$} \\
\hline & 3046 & 3046 & 3046 \\
\hline pvalue of difference & 0.387 & 0.719 & 0.627 \\
\hline \multicolumn{4}{|c|}{ E. Emphasis on Homework: } \\
\hline \multirow[t]{3}{*}{ Above median } & $-0.259 * * *$ & $-0.458 * * *$ & $-0.135 * * *$ \\
\hline & {$[0.071]$} & {$[0.067]$} & {$[0.025]$} \\
\hline & 1965 & 1965 & 1965 \\
\hline \multirow[t]{3}{*}{ Below median } & $-0.553 * * *$ & $-0.515^{* * *}$ & $-0.156 * * *$ \\
\hline & {$[0.053]$} & {$[0.056]$} & {$[0.020]$} \\
\hline & 3596 & 3596 & 3596 \\
\hline pvalue of difference & 0.001 & 0.515 & 0.519 \\
\hline \multicolumn{4}{|c|}{ F. Emphasis on Achievement/Behavior/Cooperation/Following Directions: } \\
\hline \multirow[t]{3}{*}{ Above median } & $-0.440 * * *$ & $-0.536 * * *$ & $-0.156 * * *$ \\
\hline & {$[0.063]$} & [0.059] & {$[0.024]$} \\
\hline & 2545 & 2545 & 2545 \\
\hline Below median & $-0.412 * * *$ & $-0.458 * * *$ & $-0.133 * * *$ \\
\hline & {$[0.058]$} & {$[0.065]$} & {$[0.022]$} \\
\hline & 2928 & 2928 & 2928 \\
\hline pvalue of difference & 0.739 & 0.374 & 0.476 \\
\hline G. Time spent on Phy & & & \\
\hline Above median & $-0.460 * * *$ & $-0.489 * * *$ & $-0.177 * * *$ \\
\hline & {$[0.070]$} & [0.067] & {$[0.025]$} \\
\hline & 2185 & 2185 & 2185 \\
\hline
\end{tabular}




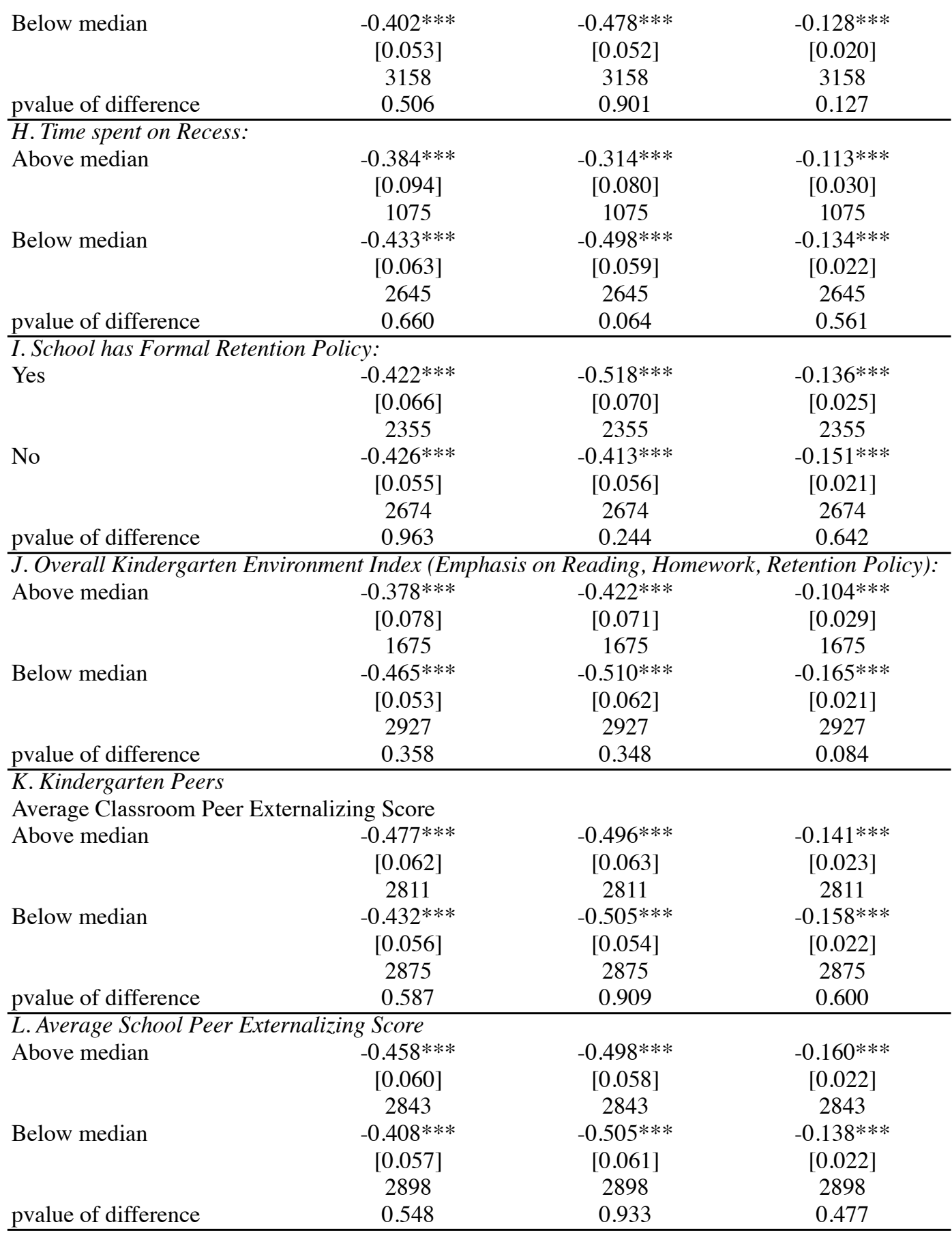

Notes: Each row corresponds to a different subset of the data. Each cell corresponds to a different regression of the outcome (indicated in each column) on a female dummy and background covariates that include race dummies (black, hisp, asian, other), age at assessment at Fall-K, age-squared, birthweight, number of older brothers, younger brothers, older sisters, younger sisters and dummies for region and urbanicity. The p-value for difference at the bottom of each panel tests whether the gender gaps for each subset of the data is statistically different. Sample is restricted to those with non-missing observations on family structure, mother's age at firstbirth, family SES, gender, the background covariates, fall-K and grade 5 teacher ratings of externalizing behavior and parental reports of school suspension in eighth grade. Observations are weighted using eighth grade parent panel weights. Robust standard errors reported. *** Significant at $1 \%$ level, **5\%*10\% 
Table 10: Teacher Gender and Female Classmates

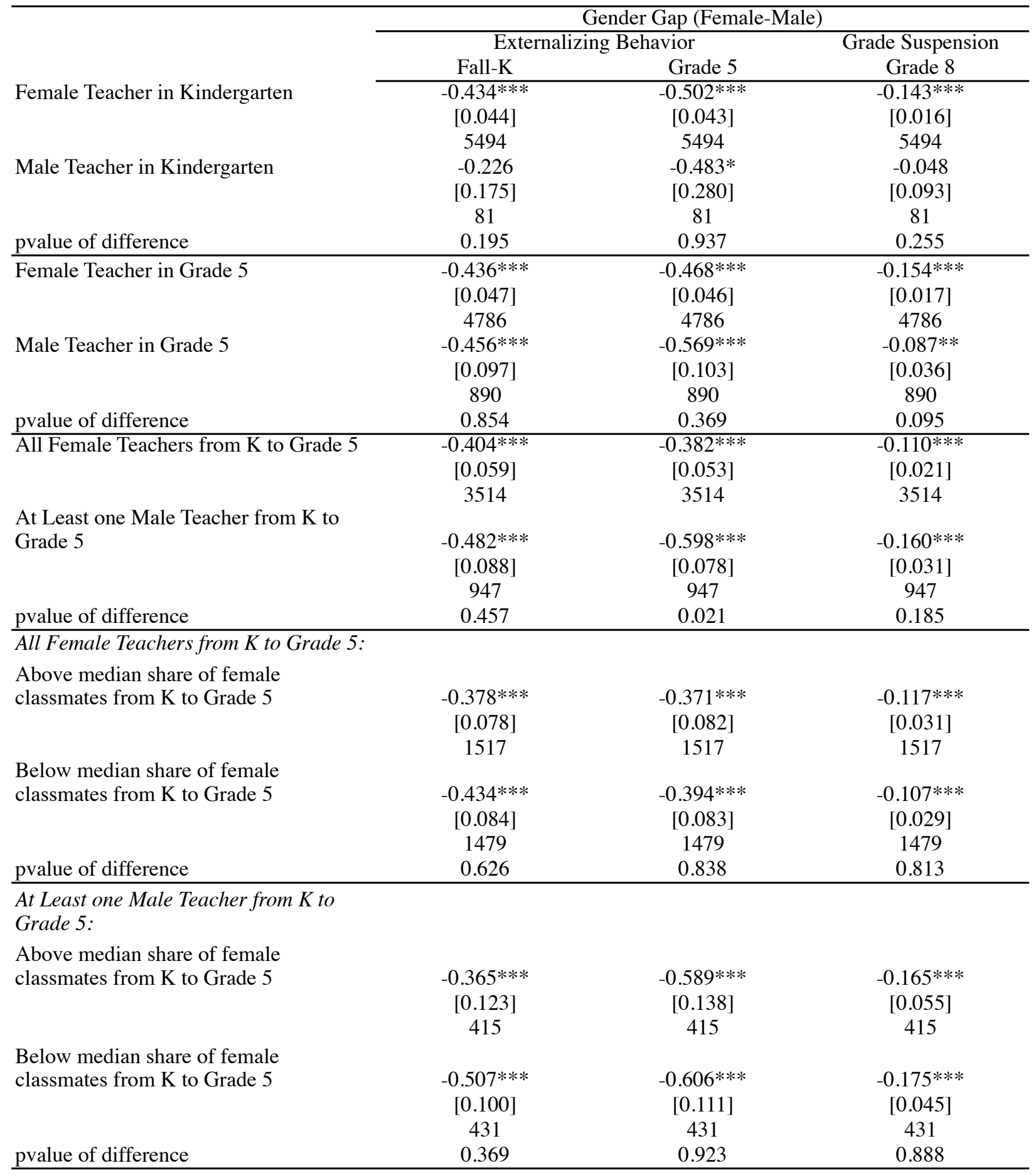

Notes: Each row corresponds to a different subset of the data. Each cell corresponds to a different regression of the outcome (indicated in each column) on a female dummy and background covariates that include race dummies (black, hisp, asian, other), age at assessment at Fall-K, age-squared, birthweight, number of older brothers, younger brothers, older sisters, younger sisters and dummies for region and urbanicity. The p-value for difference at the bottom of each panel tests whether the gender gaps for each subset of the data is statistically different. Sample is restricted to those with non-missing observations on family structure, mother's age at firstbirth, family SES, gender, the background covariates, fall-K and grade 5 teacher ratings of externalizing behavior and parental reports of school suspension in eighth grade. Observations are weighted using eighth grade parent panel weights. Robust standard errors reported. ***Significant at $1 \%$ level, $* * 5 \% * 10 \%$ 


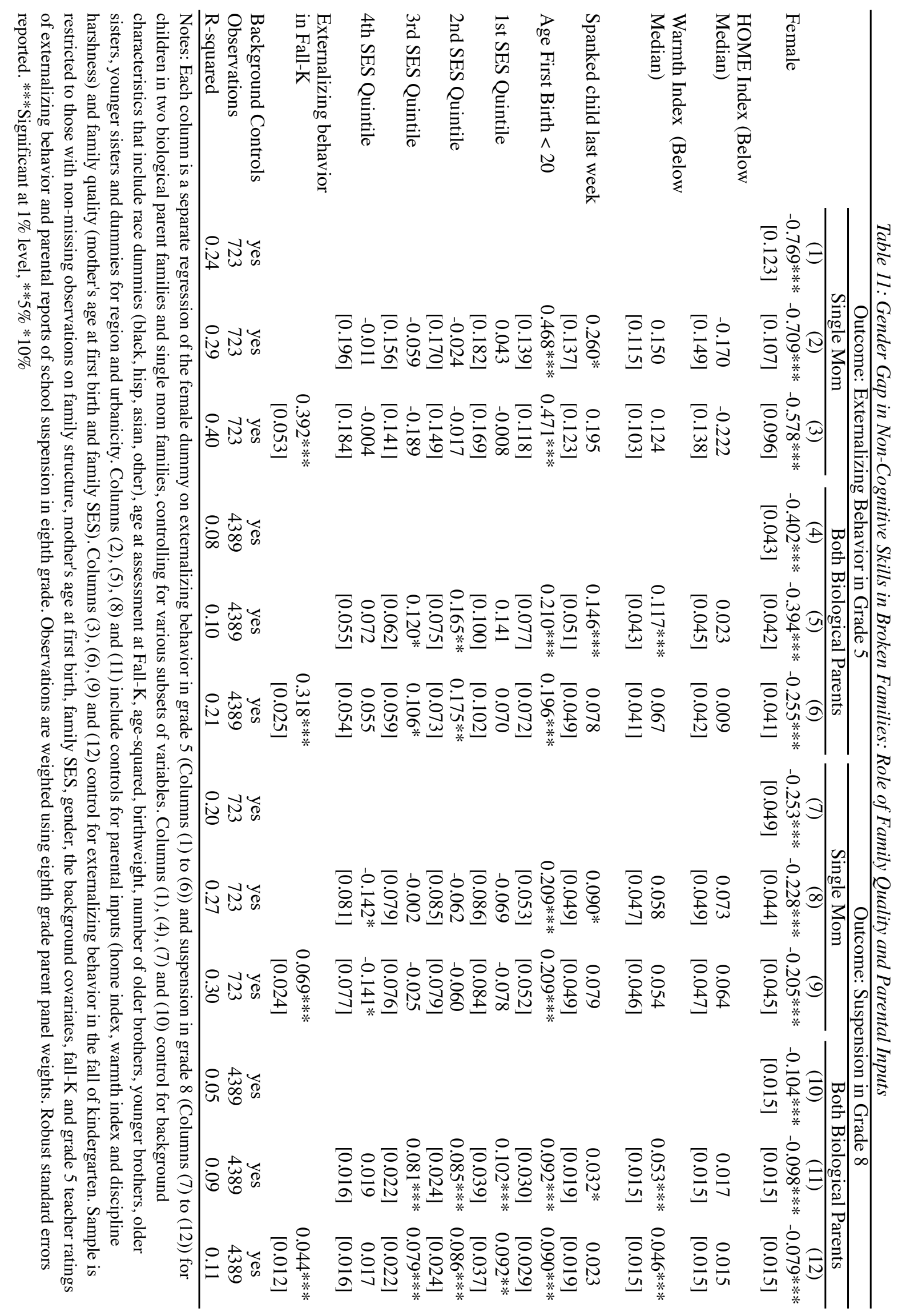




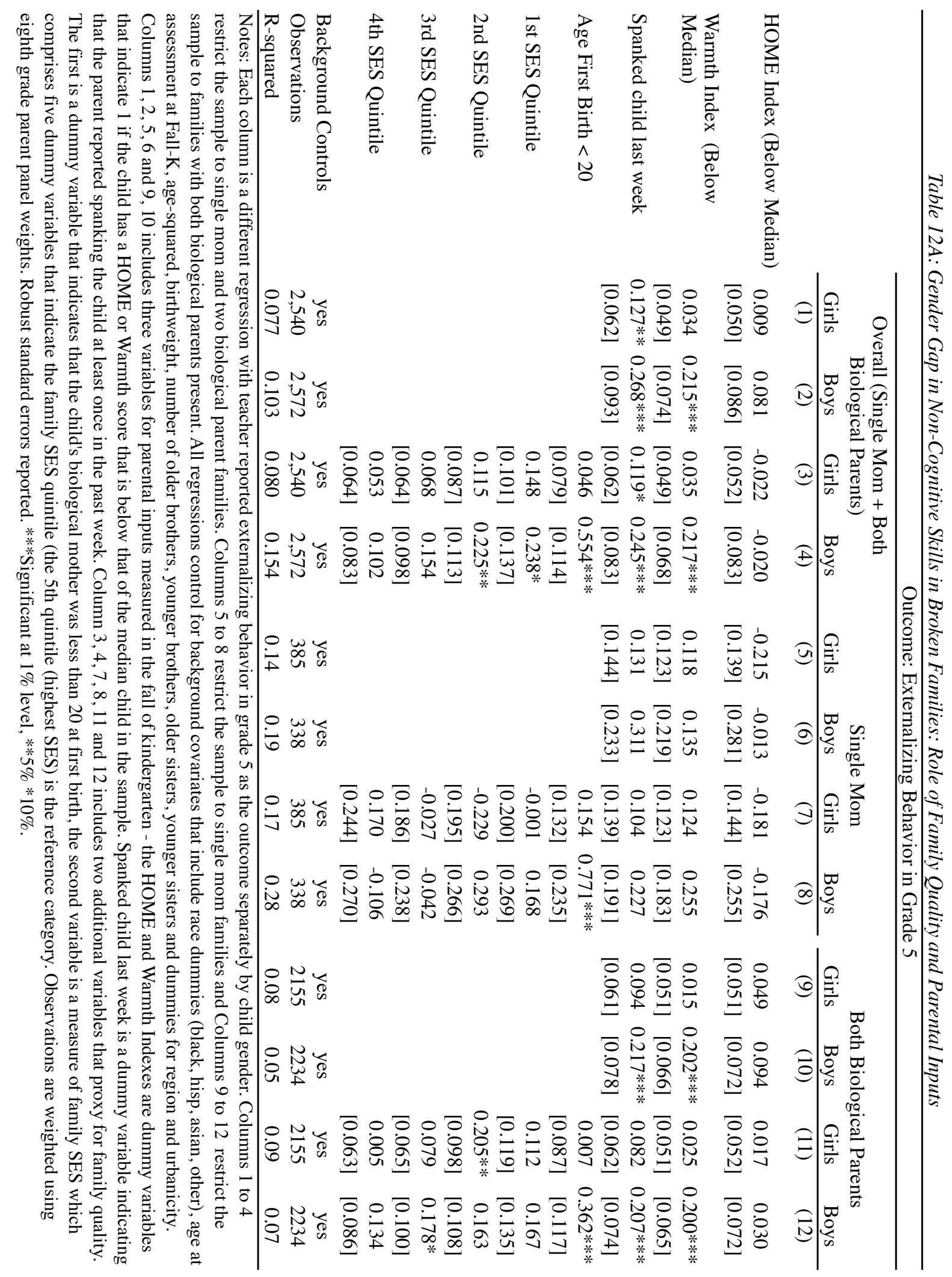




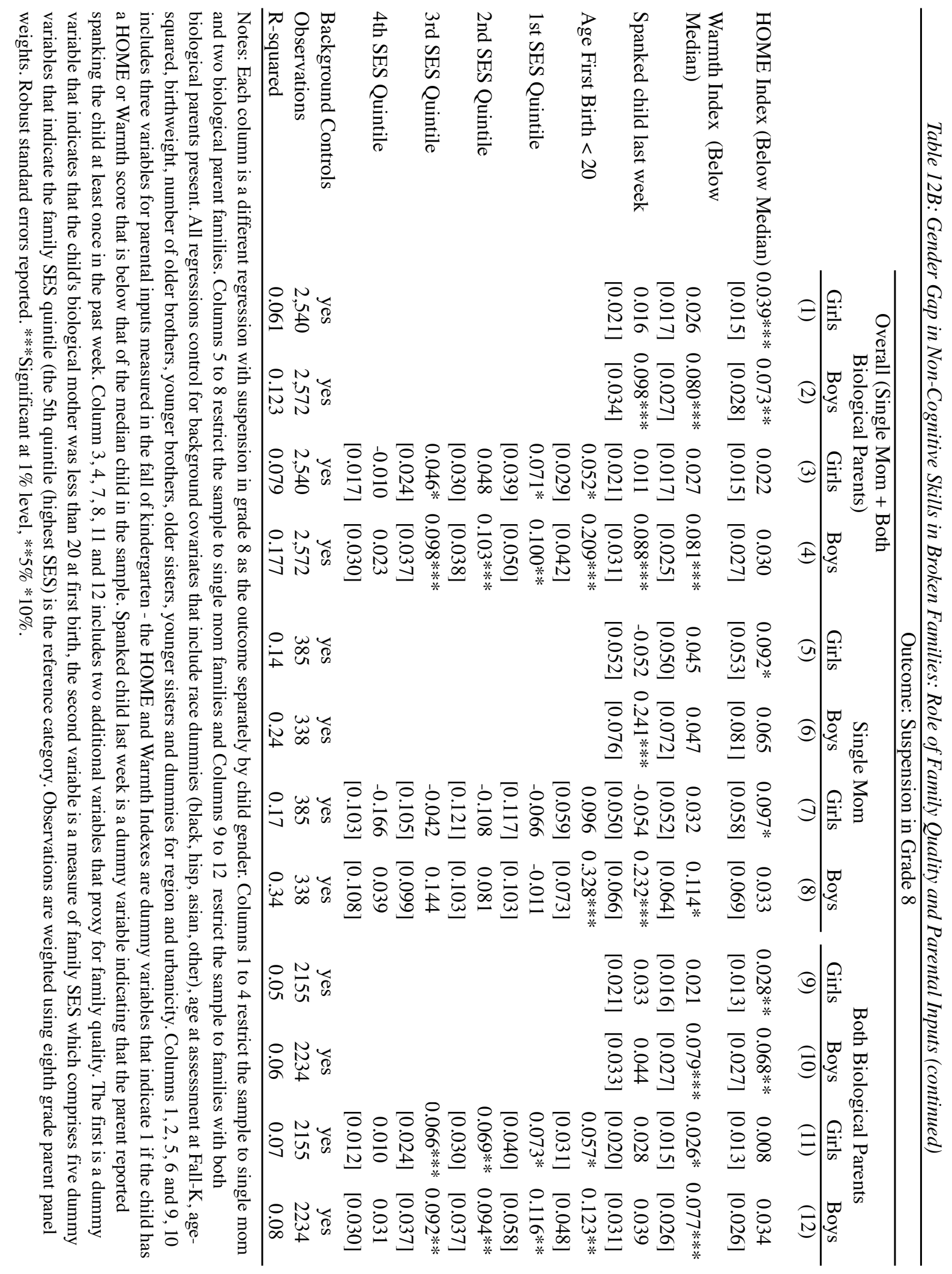




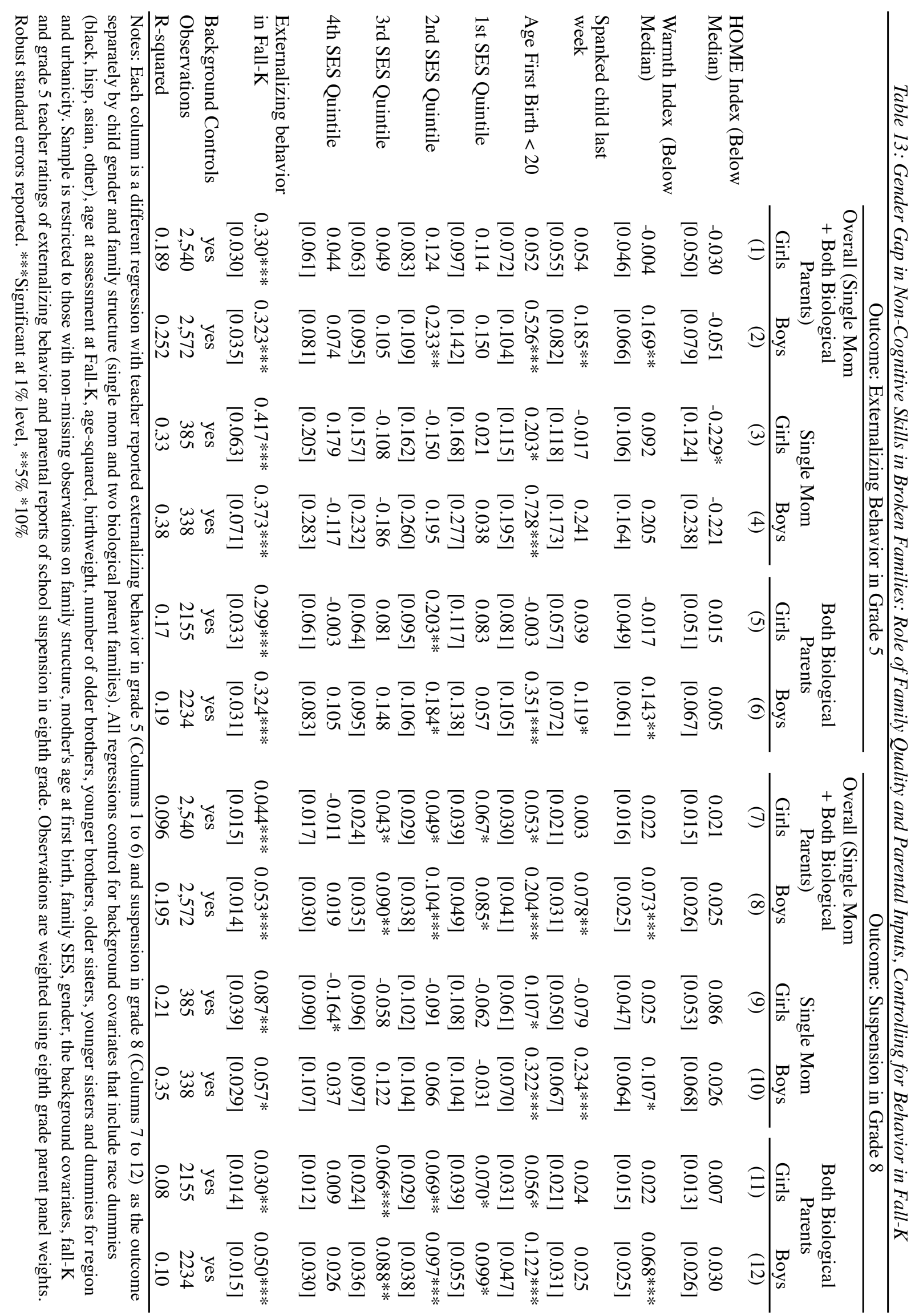




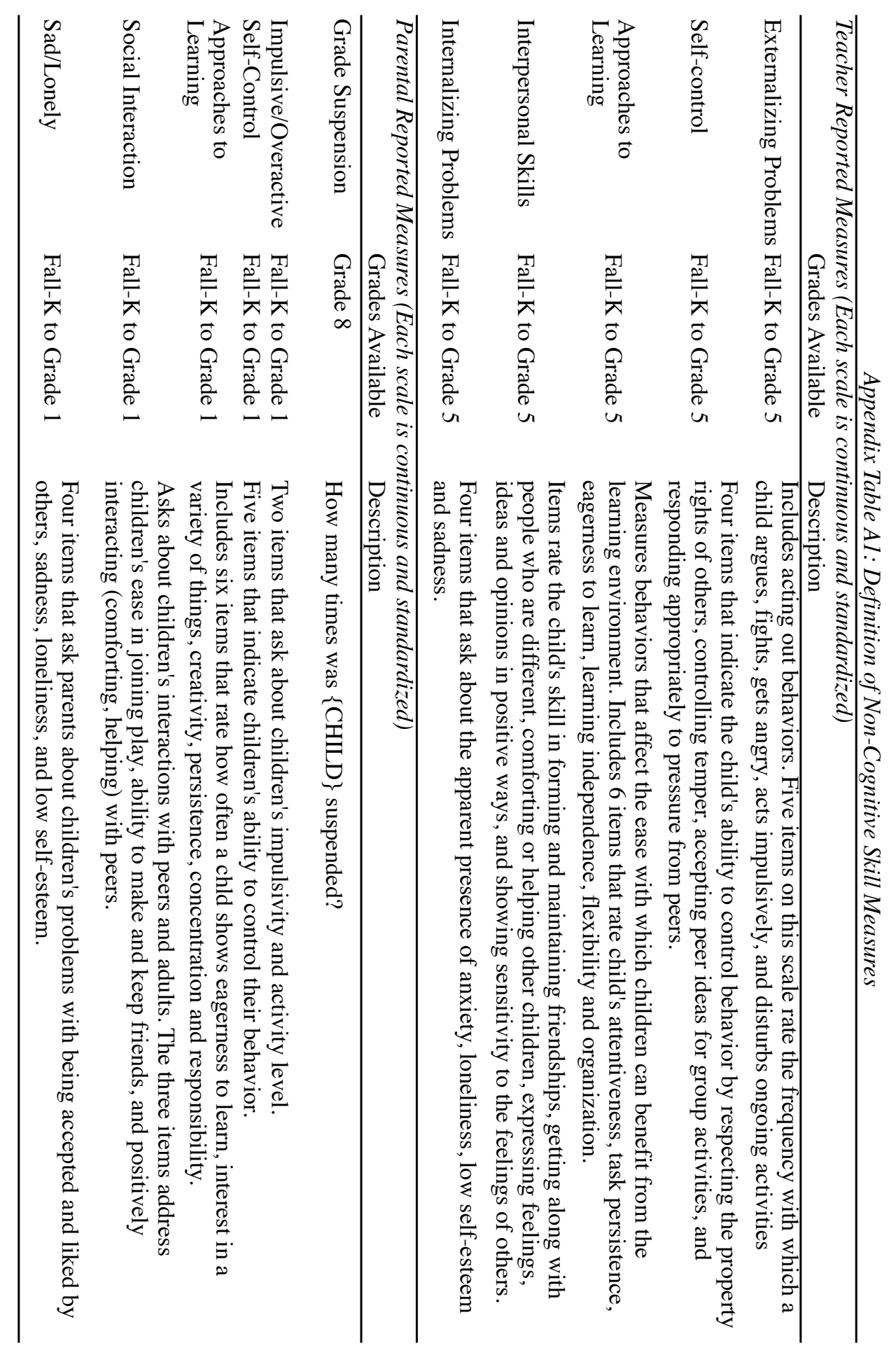


Parental Inputs/Investments

HOME Index

Emotional Supportiveness (WARMTH Index)

Child spanked last week (Spring-K)
Based on the average of the following six components. Each variable is recoded into an indicator variable. Individuals with missing responses to a component are deleted case-wise. Cronbach's alpha: 0.536 .

Component Description:

a) Parent reads to child 3 or more times a week (fall-k)

b) Child has 20 or more books (fall-k)

c) Visited the library with child in the past month (spring-k)

d) Gone to a play, concert, or other live show with child in the past month (spring-k)

e) Visited an art gallery, museum, or historical site with child in the past month (spring-k)

f) Child participated in an activity outside school hours such as dance lessons, athletic events, organized clubs, music lessons, drama classes, art lessons, organized performing, craft classes or language classes (spring-k)

Based on the sum of parental responses to the following questions in Spring-K. Each question was recoded such that 0 indicated the most negative response and 3 indicated the warmest response. The scale had a total score of 39. Individuals with missing components were deleted case-wise. Cronbach's alpha: 0.70 .

Is the statement (1) completely true, (2) mostly true, (3) somewhat true, (4) not at all true

a) Child and I often have warm, close times together

b) Most of the times I feel that child likes me and wants to be near me

c) I am usually too busy to joke and play around with child

d) Even when I'm in a bad mood, I show child a lot of love

e) By the end of a long day, I find it hard to be warm and loving toward child

f) I express affection by hugging, kissing and holding child

g) Being a parent is harder than I thought it would be

h) Child does things that really bother me

i) I find myself giving up more of my life to meet child's needs than I ever expected

j) I feel trapped by my responsibilities as a parent

k) I am often feel angry with child

1) Child seems harder to care for than most

m) I find taking care of a young child more work than pleasure

Sometimes kids mind pretty well and sometimes they don't. About how many times, if any, have you spanked $\{$ CHILD $\}$ in the past week? Variable recoded into a dummy variable that indicated 1 if child was spanked one or more times in the past week and 0 if never spanked. 
Emphasis on Reading and Math (Spring-K):
Minutes per week teacher spent on reading and math. Computed based on answers to the following questions:

a) How many times a week do children in your class usually work on lessons or projects in reading (mathematics)

b) How many minutes a day do children in your class usually work on lessons or projects in reading (mathematics)

Homework should be given to kindergarten children almost every day. Answers range from 1: Strongly Disagree to 5: Strongly agree.

\section{(Spring-K):}

Emphasis on

Achievement/Behavior/Cooper ation/Following Directions (Spring-K):

How important is each of the following in evaluating the children in your classes? Each response ranges from 1: Not important to 4: Extremely important. The index is constructed based on taking the average of the four answers.

a) Individual child's achievement relative to the rest of the class

b) Classroom behavior or conduct

c) Cooperativeness with other children

d) Ability to follow directions

Time spent on Physical Education (Spring-K):
Minutes per week spent on physical education. Computed based on anwers to the following questions:

a) How many times each week do children in your class usually have physical education?

b) How much time each day do children in your class usually spend when they participate in physical education?
Time spent on Recess (Spring$\mathrm{K})$ :

Minutes per week spent on recess. Computed based on answers to the following questions:

a) In a typical day, how much time does your child spend in the following activities? Recess

b) How many days a week do children have recess?

School has Formal Retention Policy (Spring-K):
Which of the following statements describe your school's grade retention practices or policies? This school has a formal policy (True/False) 
Appendix Table A3: Parental Ratings of Non-cognitive Skills

\begin{tabular}{|c|c|c|c|}
\hline & Girls & Boys & Difference (Girls-Boys) \\
\hline \multicolumn{4}{|l|}{ Impulsiveness } \\
\hline \multirow[t]{2}{*}{ Fall Kindergarten } & -0.141 & 0.135 & $-0.275 * * *$ \\
\hline & $(0.907)$ & $(1.065)$ & {$[0.045]$} \\
\hline \multirow[t]{2}{*}{ Spring Kindergarten } & -0.129 & 0.124 & $-0.253 * * *$ \\
\hline & $(0.926)$ & $(1.051)$ & {$[0.045]$} \\
\hline \multirow[t]{2}{*}{ Grade 1} & -0.159 & 0.152 & $-0.311 * * *$ \\
\hline & $(0.899)$ & $(1.066)$ & {$[0.046]$} \\
\hline \multicolumn{4}{|l|}{ Self-Control } \\
\hline \multirow[t]{2}{*}{ Fall Kindergarten } & 0.080 & -0.077 & $0.157 * * *$ \\
\hline & $(0.964)$ & $(1.027)$ & {$[0.046]$} \\
\hline \multirow[t]{2}{*}{ Spring Kindergarten } & 0.073 & -0.070 & $0.142 * * *$ \\
\hline & $(0.988)$ & $(1.007)$ & {$[0.046]$} \\
\hline \multirow[t]{2}{*}{ Grade 1} & 0.091 & -0.087 & $0.178 * * *$ \\
\hline & $(0.941)$ & $(1.046)$ & {$[0.046]$} \\
\hline \multicolumn{4}{|l|}{ Approaches to Learning } \\
\hline \multirow[t]{2}{*}{ Fall Kindergarten } & 0.106 & -0.102 & $0.208 * * *$ \\
\hline & $(0.959)$ & $(1.027)$ & {$[0.043]$} \\
\hline \multirow[t]{2}{*}{ Spring Kindergarten } & 0.147 & -0.141 & $0.288 * * *$ \\
\hline & $(0.975)$ & $(1.004)$ & {$[0.044]$} \\
\hline \multirow[t]{2}{*}{ Grade 1} & 0.123 & -0.118 & $0.242 * * *$ \\
\hline & $(1.000)$ & $(0.986)$ & {$[0.044]$} \\
\hline \multicolumn{4}{|l|}{ Social Skills } \\
\hline \multirow[t]{2}{*}{ Fall Kindergarten } & 0.061 & -0.058 & $0.119 * * *$ \\
\hline & $(0.982)$ & $(1.014)$ & {$[0.045]$} \\
\hline \multirow[t]{2}{*}{ Spring Kindergarten } & 0.073 & -0.070 & $0.143 * * *$ \\
\hline & $(0.955)$ & $(1.037)$ & {$[0.044]$} \\
\hline \multirow[t]{2}{*}{ Grade 1} & 0.063 & -0.060 & $0.124 * * *$ \\
\hline & $(0.955)$ & $(1.038)$ & {$[0.044]$} \\
\hline \multicolumn{4}{|l|}{ Sad/Lonely } \\
\hline \multirow[t]{2}{*}{ Fall Kindergarten } & 0.018 & -0.017 & 0.035 \\
\hline & $(0.958)$ & $(1.038)$ & {$[0.044]$} \\
\hline \multirow[t]{2}{*}{ Spring Kindergarten } & 0.038 & -0.036 & 0.074 \\
\hline & $(0.973)$ & $(1.024)$ & {$[0.046]$} \\
\hline \multirow[t]{2}{*}{ Grade 1} & -0.029 & 0.028 & -0.058 \\
\hline & $(0.940)$ & $(1.054)$ & [0.049] \\
\hline
\end{tabular}

Notes: Summary statistics are based on the restricted sample of children with non-missing observations for each outcome. Parental ratings are standardized to have a mean of zero and standard deviation one in the weighted sample after imposing the sample restrictions. Please refer to the text for sample restrictions. Observations are weighted using eighth grade parent panel weights (C1_7FP0). Robust standard errors are reported for differences in the means across genders ***significant at $1 \% * * 5 \% * 10 \%$. 
Appendix Table A4: Summary Statistics for Child's Background Characteristics

\begin{tabular}{|c|c|c|c|c|}
\hline & Full Sample & Girls & Boys & $\begin{array}{l}\text { Difference (Girls- } \\
\text { Boys) }\end{array}$ \\
\hline \multirow{2}{*}{ White } & 0.595 & 0.583 & 0.607 & -0.024 \\
\hline & $(0.491)$ & $(0.493)$ & $(0.488)$ & {$[0.021]$} \\
\hline \multirow[t]{2}{*}{ Black } & 0.160 & 0.157 & 0.162 & -0.005 \\
\hline & $(0.367)$ & $(0.364)$ & $(0.369)$ & {$[0.019]$} \\
\hline \multirow[t]{2}{*}{ Hisp } & 0.173 & 0.178 & 0.168 & 0.009 \\
\hline & $(0.378)$ & $(0.382)$ & $(0.374)$ & {$[0.014]$} \\
\hline \multirow[t]{2}{*}{ Asian } & 0.031 & 0.038 & 0.024 & $0.015^{* *}$ \\
\hline & $(0.173)$ & $(0.192)$ & $(0.152)$ & {$[0.007]$} \\
\hline \multirow[t]{2}{*}{ Other } & 0.041 & 0.044 & 0.038 & 0.005 \\
\hline & $(0.198)$ & $(0.205)$ & $(0.192)$ & {$[0.007]$} \\
\hline \multirow{2}{*}{$\begin{array}{l}\text { Assessment Age at } \\
\text { Fall K (in months) }\end{array}$} & & & & \\
\hline & $\begin{array}{l}68.461 \\
(4.293)\end{array}$ & $\begin{array}{l}68.162 \\
(4.162)\end{array}$ & $\begin{array}{l}68.748 \\
(4.397)\end{array}$ & $\begin{array}{c}-0.586 * * * \\
{[0.187]}\end{array}$ \\
\hline \multirow{2}{*}{$\begin{array}{l}\text { Birthweight (in } \\
\text { pounds) }\end{array}$} & & & & \\
\hline & $\begin{array}{c}7.411 \\
(1.332)\end{array}$ & $\begin{array}{c}7.307 \\
(1.293)\end{array}$ & $\begin{array}{c}7.511 \\
(1.361)\end{array}$ & $\begin{array}{c}-0.204 * * * \\
{[0.059]}\end{array}$ \\
\hline $\begin{array}{l}\text { Number of younger } \\
\text { brothers }\end{array}$ & $\begin{array}{c}0.269 \\
(0.501)\end{array}$ & $\begin{array}{c}0.253 \\
(0.474)\end{array}$ & $\begin{array}{c}0.284 \\
(0.524)\end{array}$ & $\begin{array}{c}-0.031 \\
{[0.022]}\end{array}$ \\
\hline \multirow{2}{*}{$\begin{array}{l}\text { Number of older } \\
\text { brothers }\end{array}$} & & & & \\
\hline & $\begin{array}{c}0.459 \\
(0.706)\end{array}$ & $\begin{array}{c}0.436 \\
(0.689)\end{array}$ & $\begin{array}{c}0.480 \\
(0.721)\end{array}$ & $\begin{array}{c}-0.043 \\
{[0.029]}\end{array}$ \\
\hline $\begin{array}{l}\text { Number of younger } \\
\text { sisters }\end{array}$ & $\begin{array}{c}0.254 \\
(0.500)\end{array}$ & $\begin{array}{c}0.266 \\
(0.523)\end{array}$ & $\begin{array}{c}0.242 \\
(0.477)\end{array}$ & $\begin{array}{c}0.024 \\
{[0.022]}\end{array}$ \\
\hline $\begin{array}{l}\text { Number of older } \\
\text { sisters }\end{array}$ & $\begin{array}{c}0.430 \\
(0.680)\end{array}$ & $\begin{array}{c}0.429 \\
(0.679)\end{array}$ & $\begin{array}{c}0.431 \\
(0.682)\end{array}$ & $\begin{array}{c}-0.002 \\
{[0.027]}\end{array}$ \\
\hline Northeast & $\begin{array}{c}0.182 \\
(0.386)\end{array}$ & $\begin{array}{l}0.195 \\
(0.396)\end{array}$ & $\begin{array}{c}0.171 \\
(0.376)\end{array}$ & $\begin{array}{c}0.024 \\
{[0.015]}\end{array}$ \\
\hline Midwest & $\begin{array}{c}0.234 \\
(0.424)\end{array}$ & $\begin{array}{c}0.234 \\
(0.424)\end{array}$ & $\begin{array}{c}0.234 \\
(0.424)\end{array}$ & $\begin{array}{c}-0.000 \\
{[0.017]}\end{array}$ \\
\hline South & $\begin{array}{c}0.388 \\
(0.487)\end{array}$ & $\begin{array}{c}0.368 \\
(0.482)\end{array}$ & $\begin{array}{c}0.408 \\
(0.491)\end{array}$ & $\begin{array}{l}-0.039^{*} \\
{[0.022]}\end{array}$ \\
\hline West & $\begin{array}{c}0.195 \\
(0.396)\end{array}$ & $\begin{array}{c}0.203 \\
(0.402)\end{array}$ & $\begin{array}{c}0.187 \\
(0.390)\end{array}$ & $\begin{array}{c}0.016 \\
{[0.016]}\end{array}$ \\
\hline City & $\begin{array}{c}0.356 \\
(0.479)\end{array}$ & $\begin{array}{c}0.358 \\
(0.479)\end{array}$ & $\begin{array}{c}0.354 \\
(0.478)\end{array}$ & $\begin{array}{c}0.003 \\
{[0.020]}\end{array}$ \\
\hline Suburb/Town & $\begin{array}{c}0.431 \\
(0.495)\end{array}$ & $\begin{array}{c}0.425 \\
(0.495)\end{array}$ & $\begin{array}{c}0.435 \\
(0.496)\end{array}$ & $\begin{array}{c}-0.010 \\
{[0.022]}\end{array}$ \\
\hline Rural & $\begin{array}{c}0.214 \\
(0.410)\end{array}$ & $\begin{array}{c}0.217 \\
(0.412)\end{array}$ & $\begin{array}{c}0.211 \\
(0.408)\end{array}$ & $\begin{array}{c}0.006 \\
{[0.016]}\end{array}$ \\
\hline
\end{tabular}

Notes: Summary statistics are based on the restricted sample of children with non-missing observations for each outcome. Please refer to the text for sample restrictions. Observations are weighted by eighth grade parent panel weights (C1_7FP0). Robust standard errors are reported for differences across gender $* * *$ significant at $1 \%$ level $* * 5 \%$ level $* 1 \%$ level. 


\begin{tabular}{|c|c|c|c|}
\hline & \multicolumn{3}{|c|}{ Gender Gap (Female-Male) } \\
\hline & \multicolumn{2}{|c|}{ Externalizing Behavior } & \multirow{2}{*}{$\begin{array}{c}\text { Grade Suspension } \\
\text { Grade } 8 \\
\end{array}$} \\
\hline & Fall-K & Grade 5 & \\
\hline \multicolumn{4}{|c|}{ A. Regulated Kindergarten Environment (> median on Kindergarten Index) } \\
\hline \multicolumn{4}{|c|}{ Above median age at } \\
\hline \multirow[t]{3}{*}{ kindergarten entry } & $-0.359 * * *$ & $-0.484 * * *$ & $-0.120 * * *$ \\
\hline & {$[0.114]$} & {$[0.102]$} & {$[0.042]$} \\
\hline & 690 & 690 & 690 \\
\hline \multicolumn{4}{|l|}{ Below median age at } \\
\hline \multirow[t]{3}{*}{ kindergarten entry } & $-0.369 * * *$ & $-0.375 * * *$ & $-0.086 * *$ \\
\hline & {$[0.100]$} & {$[0.088]$} & {$[0.035]$} \\
\hline & 985 & 985 & 985 \\
\hline pvalue of difference & 0.950 & 0.416 & 0.543 \\
\hline \multicolumn{4}{|c|}{ B. Less Regulated Kindergarten Environment ( $<$ median on Kindergarten Index) } \\
\hline \multicolumn{4}{|c|}{ Above median age at } \\
\hline \multirow[t]{3}{*}{ kindergarten entry } & $-0.529 * * *$ & $-0.423 * * *$ & $-0.127 * * *$ \\
\hline & {$[0.078]$} & {$[0.074]$} & {$[0.026]$} \\
\hline & 1307 & 1307 & 1307 \\
\hline \multicolumn{4}{|l|}{ Below median age at } \\
\hline \multirow[t]{3}{*}{ kindergarten entry } & $-0.407 * * *$ & $-0.573 * * *$ & $-0.188 * * *$ \\
\hline & [0.069] & [0.091] & {$[0.028]$} \\
\hline & 1619 & 1619 & 1619 \\
\hline pvalue of difference & 0.242 & 0.198 & 0.115 \\
\hline \multicolumn{4}{|c|}{ C. Regulated Kindergarten Environment (> median on Kindergarten Index) } \\
\hline \multirow{4}{*}{$\begin{array}{l}\text { Above median predicted age } \\
\text { at kindergarten entry }\end{array}$} & & & \\
\hline & $-0.417 * * *$ & $-0.596 * * *$ & $-0.169 * * *$ \\
\hline & {$[0.114]$} & {$[0.101]$} & [0.044] \\
\hline & 652 & 652 & 652 \\
\hline \multirow{4}{*}{$\begin{array}{l}\text { Below median predicted age } \\
\text { at kindergarten entry }\end{array}$} & & & \\
\hline & $-0.405^{* * *}$ & $-0.257 * *$ & -0.014 \\
\hline & {$[0.120]$} & {$[0.104]$} & [0.039] \\
\hline & 708 & 708 & 708 \\
\hline pvalue of difference & 0.939 & 0.020 & 0.008 \\
\hline \multicolumn{4}{|c|}{ D. Less Regulated Kindergarten Environment ( $<$ median on Kindergarten Index) } \\
\hline \multicolumn{4}{|c|}{$\begin{array}{l}\text { Above median predicted age } \\
\text { at kindergarten entry }\end{array}$} \\
\hline & $-0.437 * * *$ & $-0.470 * * *$ & $-0.134 * * *$ \\
\hline & [0.094] & [0.087] & {$[0.036]$} \\
\hline & 1000 & 1000 & 1000 \\
\hline \multicolumn{4}{|l|}{ Below median predicted age } \\
\hline at kindergarten entry & $-0.410 * * *$ & $-0.567 * * *$ & $-0.189 * * *$ \\
\hline & {$[0.095]$} & [0.111] & {$[0.035]$} \\
\hline & 1131 & 1131 & 1131 \\
\hline pvalue of difference & 0.841 & 0.492 & 0.275 \\
\hline
\end{tabular}

Notes: Each row corresponds to a different subset of the data. Each cell corresponds to a different regression of the outcome (indicated in each column) on a female dummy and background covariates that include race dummies (black, hisp, asian, other), age at assessment at Fall-K, age-squared, birthweight, number of older brothers, younger brothers, older sisters, younger sisters and dummies for region and urbanicity. The p-value for difference at the bottom of each panel tests whether the gender gaps for each subset of the data is statistically different. Sample is restricted to those with non-missing observations on family structure, mother's age at firstbirth, family SES, gender, the background covariates, fall-K and grade 5 teacher ratings of externalizing behavior and parental reports of school suspension in eighth grade. Observations are weighted using eighth grade parent panel weights. Robust standard errors reported. *** Significant at $1 \%$ level, $* * 5 \% * 10 \%$. 
Table A6: Gender Gap in Non-Cognitive Skills - The Role of the Home Environment (Controlling for Fall-K School Fixed Effects)

\begin{tabular}{|c|c|c|c|}
\hline & \multicolumn{3}{|c|}{ Gender Gap (Female-Male) } \\
\hline & \multicolumn{2}{|c|}{ Externalizing Behavior } & \multirow{2}{*}{$\begin{array}{c}\text { Grade Suspension } \\
\text { Grade } 8 \\
\end{array}$} \\
\hline & Fall-K & Grade 5 & \\
\hline \multirow{4}{*}{$\begin{array}{l}\text { By Family Structure: } \\
\text { Single Mother }\end{array}$} & & & \\
\hline & $-0.472 * * *$ & $-0.753 * * *$ & $-0.238 * * *$ \\
\hline & {$[0.178]$} & [0.172] & {$[0.076]$} \\
\hline & 760 & 760 & 760 \\
\hline \multirow[t]{3}{*}{ Two Biological Parents } & $-0.369 * * *$ & $-0.387 * * *$ & $-0.100 * * *$ \\
\hline & {$[0.037]$} & {$[0.035]$} & {$[0.014]$} \\
\hline & 4502 & 4502 & 4502 \\
\hline \multirow[t]{3}{*}{ Other Family Structure } & -0.528 & $-0.485^{*}$ & -0.106 \\
\hline & [0.324] & {$[0.274]$} & [0.149] \\
\hline & 479 & 479 & 479 \\
\hline $\mathrm{p}$-value for difference & 0.561 & 0.018 & 0.054 \\
\hline \multicolumn{4}{|l|}{ By SES: } \\
\hline \multirow[t]{3}{*}{ 1st Quartile (Lowest) } & $-0.462 * *$ & $-0.764 * * *$ & $-0.150 * * *$ \\
\hline & {$[0.180]$} & [0.187] & [0.056] \\
\hline & 613 & 613 & 613 \\
\hline \multirow[t]{3}{*}{ 2nd Quartile } & -0.242 & $-0.551 * * *$ & -0.118 \\
\hline & [0.149] & [0.149] & [0.072] \\
\hline & 946 & 946 & 946 \\
\hline \multirow[t]{3}{*}{ 3rd Quartile } & $-0.456 * * *$ & $-0.551 * * *$ & $-0.140 * * *$ \\
\hline & {$[0.108]$} & {$[0.091]$} & {$[0.043]$} \\
\hline & 1109 & 1109 & 1109 \\
\hline \multirow[t]{3}{*}{ 4th Quartile } & $-0.460 * * *$ & $-0.470 * * *$ & $-0.085 * * *$ \\
\hline & {$[0.086]$} & {$[0.070]$} & {$[0.029]$} \\
\hline & 1394 & 1394 & 1394 \\
\hline \multirow[t]{3}{*}{ 5th Quartile (Highest) } & $-0.360 * * *$ & $-0.344 * * *$ & $-0.091 * * *$ \\
\hline & {$[0.057]$} & {$[0.055]$} & [0.021] \\
\hline & 1679 & 1679 & 1679 \\
\hline $\mathrm{p}$-value for difference & 0.611 & 0.069 & 0.654 \\
\hline \multicolumn{4}{|l|}{ By Mother's Age at First Birth } \\
\hline \multirow{3}{*}{ Less than 20 years old } & $-0.437 * * *$ & $-0.783 * * *$ & $-0.188 * * *$ \\
\hline & {$[0.141]$} & [0.135] & {$[0.059]$} \\
\hline & 966 & 966 & 966 \\
\hline \multirow[t]{3}{*}{ More than 20 years old } & $-0.400 * * *$ & $-0.395 * * *$ & $-0.116^{* * *}$ \\
\hline & {$[0.036]$} & {$[0.033]$} & {$[0.012]$} \\
\hline & 4775 & 4775 & 4775 \\
\hline $\mathrm{p}$-value for difference & 0.746 & 0.000 & 0.131 \\
\hline
\end{tabular}

Notes: Each row corresponds to a different subset of the data. Each cell corresponds to a different regression of the outcome (indicated in each column) on a female dummy and background covariates that include race dummies (black, hisp, asian, other), age at assessment at Fall-K, age-squared, birthweight, number of older brothers, younger brothers, older sisters, younger sisters and dummies for region and urbanicity. All specifications include fixed effects for the child's school in fall-kindergarten. The p-value for difference at the bottom of each panel tests whether the gender gaps for each subset of the data is statistically different. The sample is restricted to those with non-missing observations on family structure, mother's age at firstbirth, family SES, gender, the background covariates, fall-K and grade 5 teacher ratings of externalizing behavior and parental reports of school suspension in eighth grade. Observations are weighted using eighth grade parent panel weights. Robust standard errors reported. $* * *$ Significant at $1 \%$ level, $* * 5 \% * 10 \%$ 


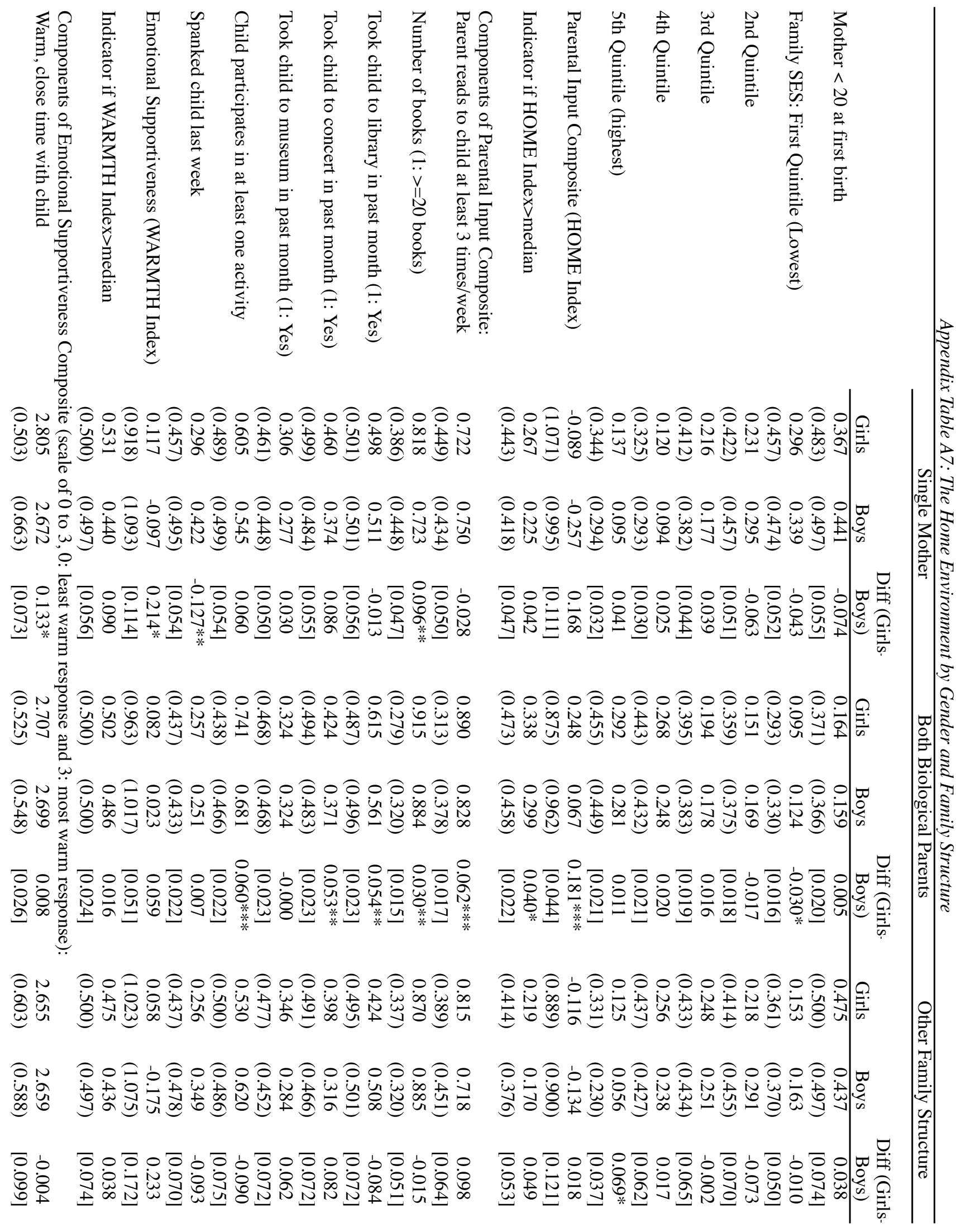




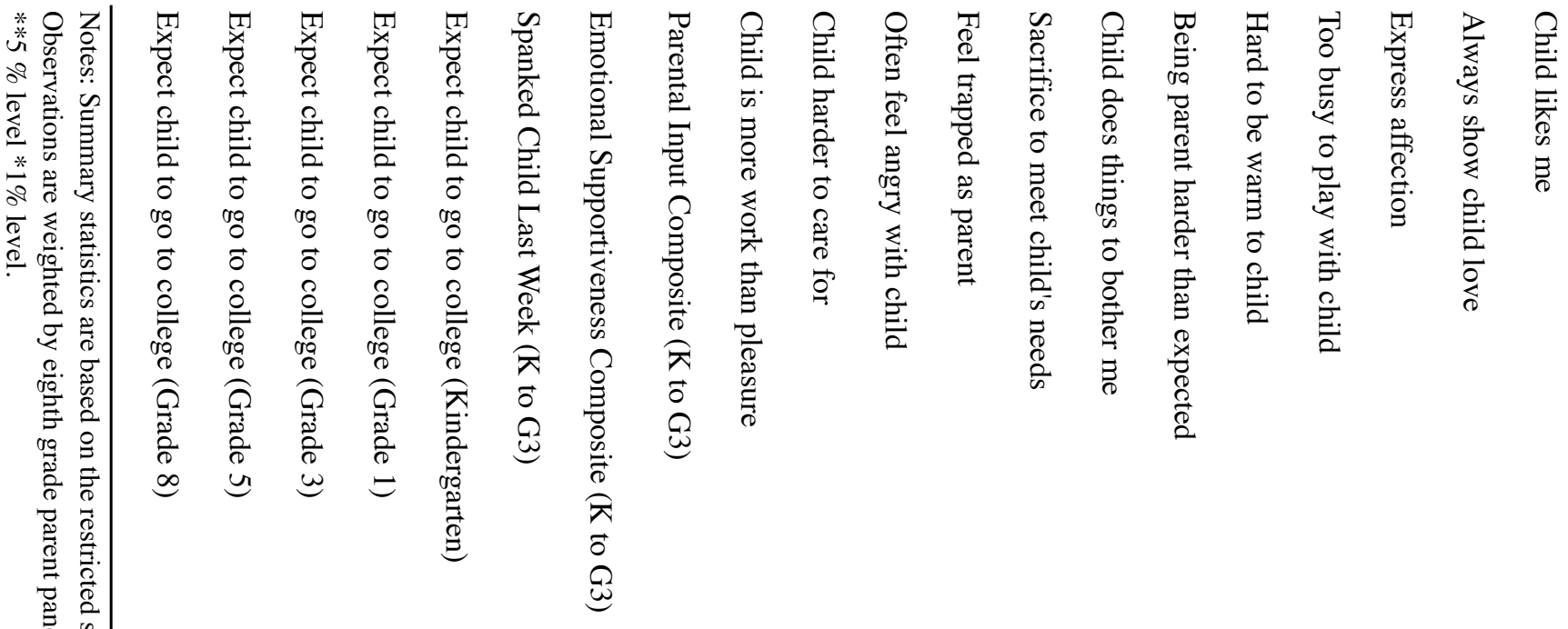

¿

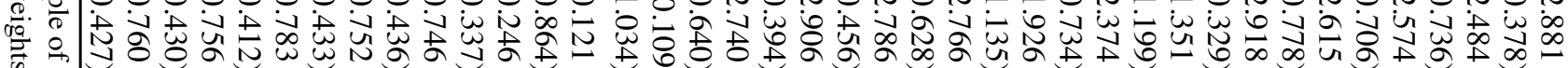

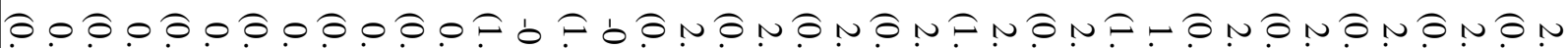

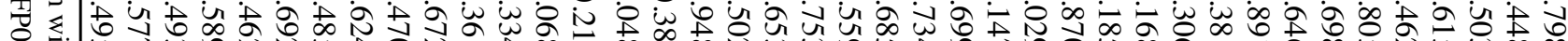

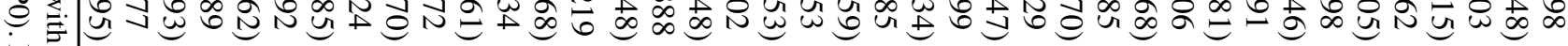

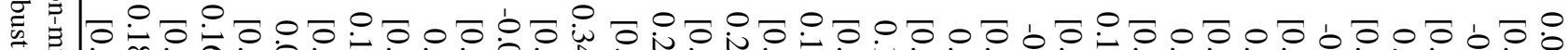
至

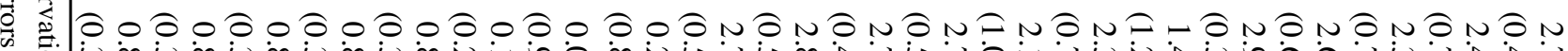

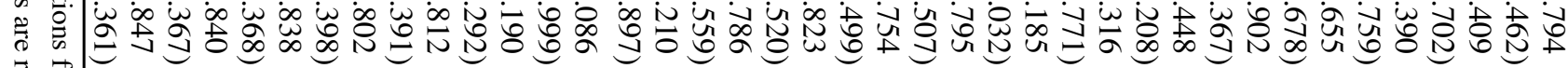

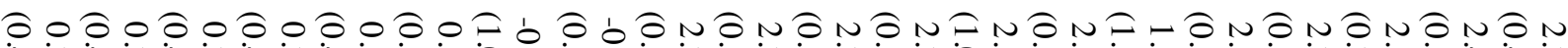
ס * $*$ *

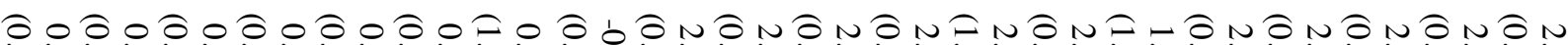

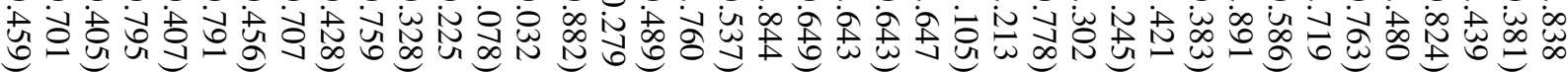
危 $\cong \overrightarrow{0}$ 
Appendix Table A8: Time Spent on Childcare by Mother's Marital Status and Family Structure Panel A: All Children Less than Five Years Old

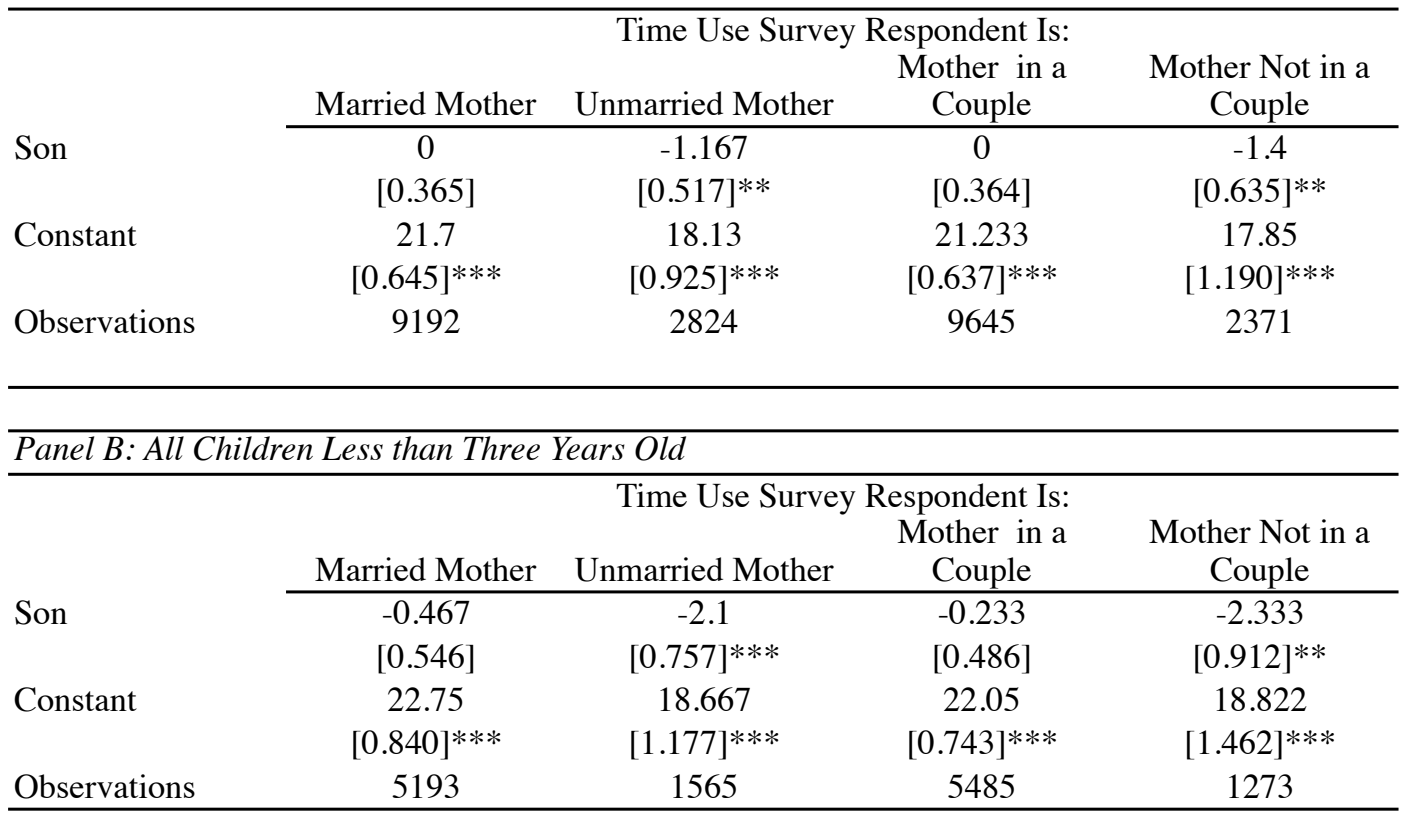

Notes: Data source is American Time Use Survey (ATUS) 2003-2010. Results are based on a median regression analysis. The outcome is the total hours spent per week on childcare. Also included in each regression are: total number of children under 18 in the family roster, child age dummies, week-end dummy. Standard errors are in brackets. $* * *$ Significant at $1 \%$ level, $* * 5 \% * 10 \%$. 


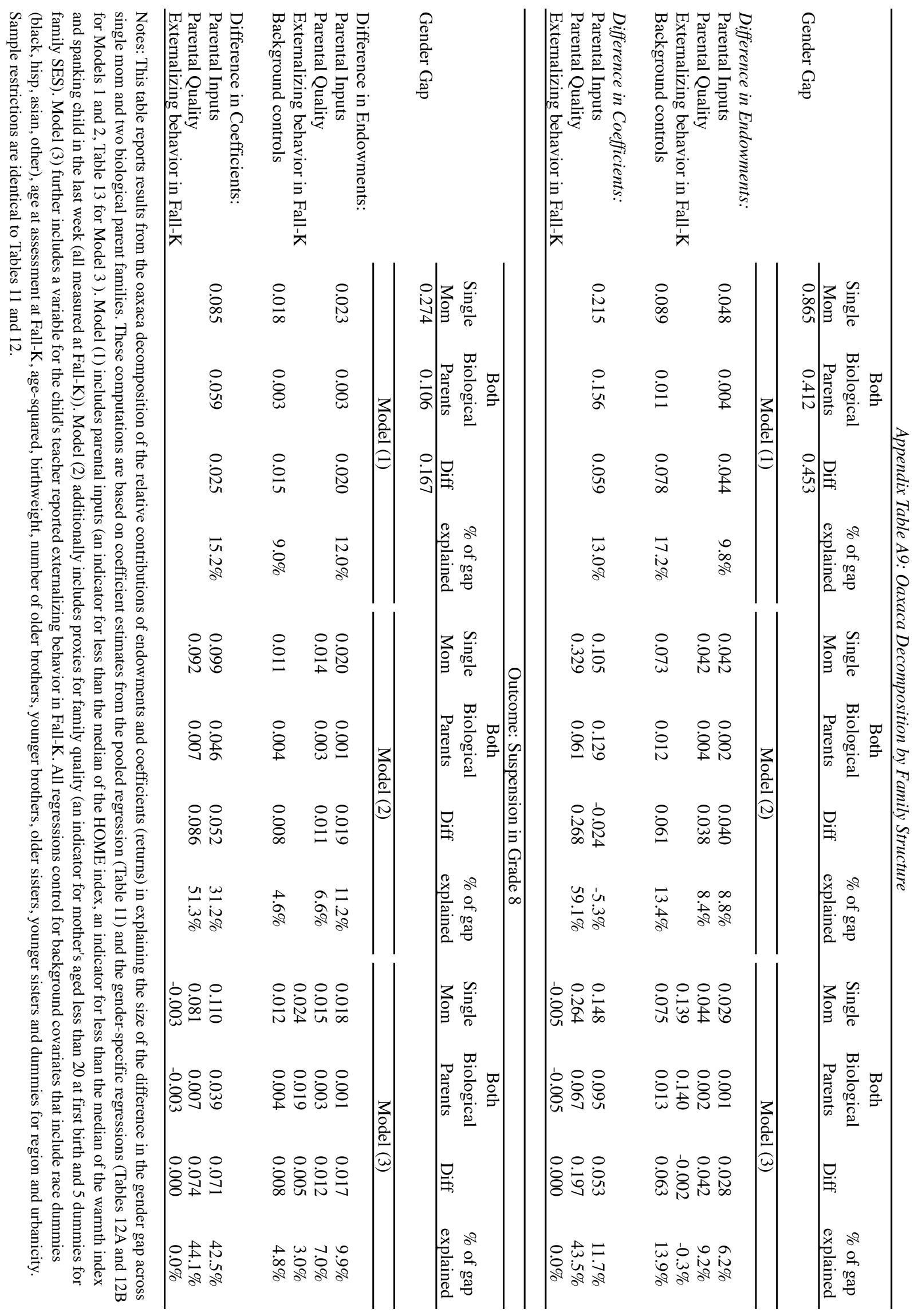




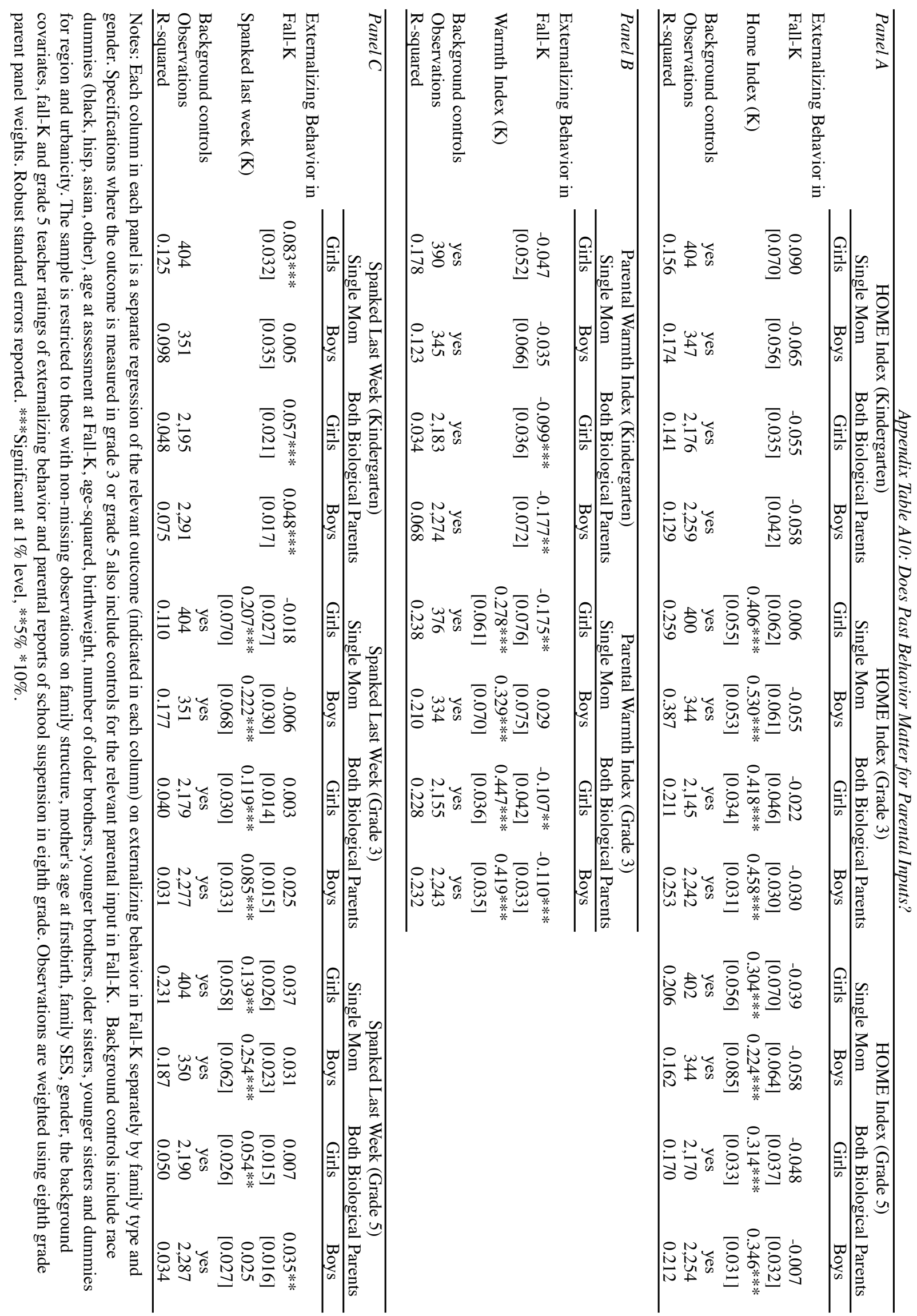

